\title{
A novel fault diagnosis technique for enhancing maintenance and reliability of rotating machines
}

DOI:

$10.1177 / 1475921715604388$

\section{Document Version}

Accepted author manuscript

Link to publication record in Manchester Research Explorer

\section{Citation for published version (APA):}

Yunusa-Kaltungo, A., Sinha, J., \& Nembhard, A. (2015). A novel fault diagnosis technique for enhancing maintenance and reliability of rotating machines. Structural Health Monitoring, 14(6), 604-621.

https://doi.org/10.1177/1475921715604388

\section{Published in:}

Structural Health Monitoring

\section{Citing this paper}

Please note that where the full-text provided on Manchester Research Explorer is the Author Accepted Manuscript or Proof version this may differ from the final Published version. If citing, it is advised that you check and use the publisher's definitive version.

\section{General rights}

Copyright and moral rights for the publications made accessible in the Research Explorer are retained by the authors and/or other copyright owners and it is a condition of accessing publications that users recognise and abide by the legal requirements associated with these rights.

\section{Takedown policy}

If you believe that this document breaches copyright please refer to the University of Manchester's Takedown Procedures [http://man.ac.uk/04Y6Bo] or contact uml.scholarlycommunications@manchester.ac.uk providing relevant details, so we can investigate your claim.

\section{OPEN ACCESS}




\title{
A novel faults diagnosis technique for enhancing maintenance and reliability of rotating machines
}

\author{
Akilu Yunusa-Kaltungo, Jyoti K. Sinha*, Adrian D. Nembhard \\ Dynamics Laboratory, School of Mechanical, Aerospace and Civil Engineering, The University of Manchester, Manchester M13 9PL, UK \\ E-mail addresses: $\quad$ akilu.kaltungo@manchester.ac.uk (A. Yunusa-Kaltungo), jyoti.sinha@manchester.ac.uk (J.K. Sinha), \\ adrian.nembhard@postgrad.manchester.ac.uk (A.D. Nembhard)
}

\begin{abstract}
Equipment standardisation as a cost-effective means of rationalising maintenance spares has significantly increased the existence of several identical (similar components and configurations) 'as installed' machines in most industrial sites. However, the dynamic behaviours of such identical machines usually differ due to variations in their foundation flexibilities, which is perhaps why separate analysis is often required for each machine during faults diagnosis. In practise, the faults diagnosis process is even further complicated by the fact that analysis is often conducted at individual measurement locations for the different speeds, since a significant number of rotating machines operate at various speeds. Hence, through the experimental simulation of a similar practical scenario of two identically configured 'as installed' rotating machines with different foundation flexibilities, the present study proposes a simplified vibration-based faults diagnosis (FD) technique that may be valuable for faults detection irrespective of foundation flexibilities or operating speeds. On both experimental rigs with different foundation flexibilities, several common rotor-related faults were independently simulated. Data combination method was then used for computing composite higher order spectra (composite bispectrum and composite trispectrum), after which principal component analysis is used for faults separation and diagnosis of the grouped data. Hence, the current paper highlights the usefulness of the proposed FD approach for enhancing the reliability of identical 'as installed' rotating machines, irrespective of the rotating speeds and foundation flexibilities.
\end{abstract}

Key words Reliability, condition based maintenance, data fusion, composite spectra, principal component analysis, multiple speeds, multiple foundations 


\section{Abbreviations}

AI artificial intelligence

ANN artificial neural networks

BM breakdown maintenance

BS bent shaft

CB composite bispectrum

CBM condition based maintenance

CS composite spectrum

CSD cross-power spectrum density

CT composite trispectrum

EDM electric discharge machining

FD faults diagnosis

FDS faults diagnosis scenario

FRF frequency response function

FS flexible support

FT Fourier transformation

HRM healthy with residual misalignment

LB loose bearing

PC principal components

PCA principal component analysis

PCB printed circuit board

pCCS poly coherent composite spectrum

PPM planned preventive maintenance

RPM revolutions per minute

SC shaft crack

SM shaft misalignment

SR shaft rub

SVM support vector machine

VFD vibration-based faults diagnosis 


\section{Nomenclature}

A

B

B

$\mathrm{B}\left(f_{\mathrm{l}}, f_{\mathrm{m}}\right)$

$\mathrm{B}_{\alpha \beta}$

$\mathrm{C}_{1}, \mathrm{C}_{2}, \ldots, \mathrm{C}_{\mathrm{r}}$

$\mathrm{C}_{\mathrm{p}}$

$f_{\mathrm{l}}, f_{\mathrm{m}}, f_{\mathrm{n}}, f_{\mathrm{k}}$

$\mathbf{F}_{\mathrm{C}_{1}, \mathrm{~s}_{\mathrm{k}}}, \mathbf{F}_{\mathrm{C}_{2}, \mathrm{~s}_{\mathrm{k}}}, \ldots ., \mathbf{F}_{\mathrm{C}_{\mathrm{r}}, \mathrm{s}_{\mathrm{k}}}$

$\mathbf{F}_{\mathrm{S}_{1}}, \mathbf{F}_{\mathrm{S}_{2}}, \ldots, \mathbf{F}_{\mathrm{S}_{\mathrm{N}}}$

$\mathbf{F S}_{1}, \mathbf{F S}_{2}, \ldots, \mathbf{F S}_{\mathrm{B}}$

$\mathrm{n}_{\mathrm{s}}$

$\mathrm{n}_{1}$

$\mathrm{n}_{2}$

$\mathrm{P}$

$\mathrm{s}_{1}, \mathrm{~s}_{2}, \ldots \ldots, \mathrm{s}_{\mathrm{N}}$

$\mathrm{S}_{\mathrm{CCS}}\left(f_{\mathrm{k}}\right)$

$\mathrm{S}_{\mathrm{pCCS}}\left(f_{\mathrm{k}}\right)$

$S_{\mathrm{x}_{1} \gamma_{12}^{2} \mathrm{x}_{2}}^{\mathrm{r}}\left(f_{\mathrm{k}}\right), S_{\mathrm{x}_{2} \gamma_{23}^{2} \mathrm{x}_{3}}^{\mathrm{r}}\left(f_{\mathrm{k}}\right)$

$S_{\mathbf{x}_{(\mathrm{b}-1)} \gamma_{(\mathrm{b}-1) \mathrm{b}}^{2} \mathrm{x}_{\mathrm{b}}}^{\mathrm{r}}\left(f_{\mathrm{k}}\right)$

$\mathrm{t}$

$\mathrm{T}\left(f_{1}, f_{\mathrm{m}}, f_{\mathrm{n}}\right)$

$\mathrm{X}_{(\mathrm{b}-1)}^{\mathrm{r}}\left(f_{\mathrm{k}}\right), \mathrm{X}_{\mathrm{b}}^{\mathrm{r}}\left(f_{\mathrm{k}}\right)$ orthogonal matrix

number of bearings

number of flexible supports

composite bispectrum at frequencies $f_{\mathrm{l}}$ and $f_{\mathrm{m}}$

composite bispectrum at engine orders $\alpha$ and $\beta$

experimentally simulated cases

covariance matrix of $p$

frequencies

feature matrices for different experimentally simulated cases at rotor speed $s_{k}$

feature matrices at rotor speeds $s_{1}, s_{2}, \ldots . ., s_{N}$ respectively

identical 'as installed' rotating machines with flexible supports $1,2, \ldots, \mathrm{B}$

number of equal segments for Fourier transformation

observations

variables

number of measured data sets at a particular rotor speed $s_{\mathrm{k}}$

rotor speeds in revolutions per minute

coherent composite spectrum at frequency $f_{\mathrm{k}}$

poly Coherent composite spectrum at frequency $f_{\mathrm{k}}$

coherent cross-power spectrum of the rth segment between bearings 1 and 2; bearings 2 and 3 at frequency $f_{\mathrm{k}}$

coherent cross-power spectrum of the rth segment between bearings (b-1) and $\mathrm{b}$ at frequency $f_{\mathrm{k}}$

number of principal components

composite trispectrum at frequencies $f_{1}, f_{\mathrm{m}}$ and $f_{\mathrm{n}}$

Fourier transformation of $\mathrm{r}^{\text {th }}$ segment at frequency for bearings (b-1) and b respectively 
$\mathrm{X}_{\mathrm{CCS}}^{\mathrm{r}}\left(f_{\mathrm{l}}\right), \mathrm{X}_{\mathrm{CCS}}^{\mathrm{r}}\left(f_{\mathrm{m}}\right), \mathrm{X}_{\mathrm{CCS}}^{\mathrm{r}}\left(f_{\mathrm{n}}\right)$,

$\mathrm{X}_{\mathrm{CCS}}^{\mathrm{r}}\left(f_{\mathrm{k}}\right)$

$\mathrm{X}_{\mathrm{CCS}}^{\mathrm{r}^{*}}\left(f_{\mathrm{l}}+f_{\mathrm{m}}\right), \mathrm{X}_{\mathrm{CCS}}^{\mathrm{r}^{*}}\left(f_{\mathrm{l}}+f_{\mathrm{m}}+f_{\mathrm{n}}\right)$

$\mathrm{X}_{\mathrm{CCS}}^{\mathrm{r}^{*}}\left(f_{\mathrm{k}}\right)$

$\mathrm{X}_{\mathrm{pCCS}}^{\mathrm{r}}\left(f_{1}\right), \mathrm{X}_{\mathrm{pCCS}}^{\mathrm{r}}\left(f_{\mathrm{m}}\right)$

$\mathrm{X}_{\mathrm{pCCS}}^{\mathrm{r}^{*}}\left(f_{\mathrm{l}}+f_{\mathrm{m}}\right), \mathrm{X}_{\mathrm{pCCS}}^{\mathrm{r}^{*}}\left(f_{\mathrm{l}}+f_{\mathrm{m}}+f_{\mathrm{n}}\right)$

$\mathrm{X}_{1}^{\mathrm{r}}\left(f_{\mathrm{k}}\right), \mathrm{X}_{2}^{\mathrm{r}}\left(f_{\mathrm{k}}\right), \mathrm{X}_{3}^{\mathrm{r}}\left(f_{\mathrm{k}}\right), \mathrm{X}_{4}^{\mathrm{r}}\left(f_{\mathrm{k}}\right)$

$\mathrm{X} 1, \mathrm{X} 2, \mathrm{X} 3, \ldots ., \mathrm{Xq}$

$\alpha, \beta$ and $\delta$

$\gamma_{12}^{2}, \gamma_{23}^{2}, \gamma_{(\mathrm{b}-1) \mathrm{b}}^{2}$

$\Lambda$ coherent composite Fourier transformation of $\mathrm{r}^{\text {th }}$ segment at frequency $f_{\mathrm{l}}, f_{\mathrm{m}}, f_{\mathrm{n}}$ and $f_{\mathrm{k}}$

complex conjugate of the Coherent composite Fourier transformation of $\mathrm{r}^{\text {th }}$ segment at frequency $f_{(1+\mathrm{m})}$ and $f_{(1+\mathrm{m}+\mathrm{n})}$

complex conjugate of the Coherent composite Fourier transformation of $\mathrm{r}^{\text {th }}$ segment at frequency $f_{\mathrm{k}}$

poly coherent composite Fourier transformation of $\mathrm{r}^{\text {th }}$ segment at frequencies $f_{1}$ and $f_{\mathrm{m}}$

complex conjugate of poly coherent composite Fourier transformation of $\mathrm{r}^{\text {th }}$ segment at frequencies $f_{(1+\mathrm{m})}$ and $\left(f_{\mathrm{l}}+f_{\mathrm{m}}+f_{\mathrm{n}}\right)$

Fourier transformation of $\mathrm{r}^{\text {th }}$ segment at frequency for measurement locations $1-4$ respectively

individual features for " $p$ " number of observations for a particular case $\mathrm{C}_{\mathrm{r}}$ at rotor speed $\mathrm{s}_{\mathrm{k}}$

engine orders

coherence between bearings 1 and $2 ; 2$ and $3 ; \ldots$ (b-1) and $b$

diagonal matrix 


\section{Introduction}

Faults always occur in rotating machines due to the vast and severe conditions under which they operate across several industries. The lack of early detection of such faults often leads to depleted machine reliability, which could have catastrophic consequences on the safety and profitability of any organisation [1]. A maintenance activity (which has evolved over time) has always been applied for the detection and elimination of these faults. Maintenance can be described as the combination as well as synchronisation of all technical, administrative and managerial tasks directed towards ensuring that a machine adequately performs the functions for which it was acquired [2-4]. Initially, maintenance interventions (mainly repair and replace) are only conducted to restore already failed machines back to operating condition.

This type of maintenance strategy ultimately required huge investments in spares, incorporation of high levels of redundancies in plant designs, and a significantly large maintenance team. The capital intensiveness and high equipment failure levels associated with breakdown maintenance $(\mathrm{BM})$ triggered the shift towards a periodic or planned preventive maintenance (PPM) philosophy that entailed the repair of machines over a predefined time period, irrespective of machines' conditions. Although the planned preventive maintenance approach significantly reduced plant interruptions, however, the cost associated with this practise was also high. Based on this premise, maintenance experts have continuously sorted after a more effective maintenance philosophy that will only be triggered by the presence of symptomatic changes in a machine's operating conditions due to faults, such as condition-based maintenance (CBM).

In an adequately implemented and managed CBM system, the decision to repair or replace a machine is often guided by the results obtained from the analysis of measured machine operations data (e.g. vibration, temperature, sound, etc.). The reviews by Jardine et al. [5], Lee et al. [6], Heng et al. [7] and Lee et al. [8] offered extensive details and trends of commonly applied CBM diagnostic and prognostic techniques for machines. In these reviews [5-8], it was also highlighted that vibration-based faults diagnosis (VFD) techniques [9-13] are amongst the most popular, owing to the fact that different components in a machine assembly often exhibit peculiar vibration characteristics due to faults. Machinery vibration signals have been processed using time [14-15], frequency or time-frequency [16-17] domain techniques. The frequency domain signal analysis, based on Fourier transformation (FT) is one of the most conventionally applied VFD signal processing techniques in practise, since it provides the opportunity to easily identify frequency components of interest [5]. Some of the 
frequency domain vibration signal processing techniques used for faults diagnosis in rotating machines includes power spectrum [18], higher order spectra [19-24], holospectrum [25], cepstrum [26], composite spectrum [27], composite bispectrum [28], etc.

Despite the maturity of spectrum-based techniques, the quest for more profound understanding of the dynamic characteristics of vibrating systems has led to the application of model-based approaches [29] for rotating machines' faults diagnosis. These model-based approaches [29] usually involve the development and application of explicit mathematical models for simulating the behaviour of an 'as installed' machine. The emergence of very powerful computers has significantly reduced the complexity and time required to perform model-based faults diagnosis. Such technological advancements have also enhanced the ease with which researchers can reliably analyse and predict future behaviours of vibrating systems. Kerschen et al. [30] provided extensive reviews on model-based analysis of vibrating systems. Other researchers have also applied model-based approaches for analysing rotating machines faults such as unbalance and misalignment [31], rotor crack [32-34], etc. Although model-based analysis can offer more descriptive results if a precise model is built, however, it is sometimes near impossible to achieve the required precision when dealing with very complex structures [5].

In order to reduce dependence on human interference and experience, some researchers have adopted artificial intelligence (AI) techniques such as artificial neural networks (ANN) [3542], support vector machine (SVM) [43-47], and fuzzy logic [48]. ANN is basically a computational model that contains simple processing elements that are linked via a complex layer structure, thereby imitating the formation of the human brain [5]. A comprehensive review on more than a decade-long applicability of artificial neural networks in the industry was compiled by Meireless et al. [35]. Other studies have also shown the capabilities of ANN in classifying rotating machine conditions [36], detection of rotor loading conditions [37], gear faults identification [38-40], fan blade faults detection [41] as well as diagnosis of rolling element bearing faults [42]. Although AI-based techniques possess the potentials to automate VFD processes, however, studies [5, 7] have also highlighted the difficulties associated with providing physical interpretations of the trained model as well as the complexity of the training process. SVM is another popularly used AI-based technique that has proven capable of providing accurate decision results in some cases, mainly due to its augmented decision boundary and real time analysis capability [43-44]. Although SVM has been used to detect faults related to rotors [45], bearings [46], gears [38], pump valves [47], 
etc., however, studies [6] have also shown that there is still a lack of standard technique for selecting its key process (i.e. Kernel process) function. Other efforts aimed at further simplifying rotating machines' faults diagnosis using pattern recognition tools such as principal components analysis (PCA) has also been explored by some researchers [49]. The application of PCA for faults diagnosis is particularly strengthened by its ability to compress large multi-dimensional input data sets into lower dimensional but representative data sets [6]. Nembhard et al. [50] recently applied PCA for detecting and classifying rotor-related faults such as misalignment, crack and shaft rub. In this study [50], the combination of measured vibration and temperature features was explored. PCA has also been used for identifying faults related to rolling element bearings [51-52] and gears [53-55].

As valuable and significant as the contributions from these earlier studies are, they have been predominantly used to diagnose faults associated with rotating machines on single foundations and at single machine speeds. In practice however, two or more identical (similar components and configurations) rotating machines installed at different plant locations may exhibit different dynamic characteristics, due to variations in their foundation flexibilities. These differences in dynamic characteristics often require that separate analysis is conducted for each machine at the different speeds, which may complicate the faults diagnosis process. Hence, the development of a unified VFD technique that will be capable of detecting and differentiating rotating machines' faults, irrespective of foundation flexibility and machine speed is highly desirable. In the present study, the earlier [27-28] and improved [56] composite higher order spectra (i.e. composite bispectrum and composite trispectrum) data combination (in the frequency domain) techniques have been respectively used to compute faults diagnosis features for two identical flexibly supported rotating machines, operating under different faults and speeds. Through the application of a PCA-based faults diagnosis algorithm, a unified faults diagnosis technique capable of faults detection and classification, irrespective of machine speed or foundation is proposed. The proposed technique is expected to reduce the complexity and subjectivity associated with faults diagnosis at individual machine speed and foundation, which is often characterised by the appearance of several features. The study also compares the results of the diagnosis features computed using the earlier and improved composite higher order spectra approaches. Hence, detailed descriptions of the composite spectra computations, experimental rigs, vibration experiments with different faults, signal processing and the results of the proposed unified PCA-based faults diagnosis technique are presented here. 


\section{Composite Spectra Computations}

The computational approaches for the composite spectra based on both the earlier [27-28] and the proposed improved [56] methods are also described here.

\subsection{Earlier Method}

The earlier proposed method for computing the composite spectrum (CS) of a rotating machine from which vibration measurements were collected from " $b$ " number of bearing locations is [27];

$$
\mathrm{S}_{\mathrm{CCS}}\left(f_{\mathrm{k}}\right)=\frac{\sum_{\mathrm{r}=1}^{\mathrm{n}_{\mathrm{s}}} \mathbf{x}_{\mathrm{CCS}}^{\mathrm{r}}\left(f_{\mathrm{k}}\right) \mathbf{x}_{\mathrm{CCS}}^{\mathrm{r}^{*}}\left(f_{\mathrm{k}}\right)}{\mathrm{n}_{\mathrm{s}}}
$$

where $\mathrm{X}_{\mathrm{CCS}}^{\mathrm{r}}\left(f_{\mathrm{k}}\right)$ and $\mathrm{X}_{\mathrm{CCS}}^{\mathrm{r}^{*}}\left(f_{\mathrm{k}}\right)$ are respectively the coherent composite Fourier Transformation (FT) and its complex conjugate for the rth segment of the measured vibration data from " $b$ " bearing locations at frequency, $f_{\mathrm{k}} \cdot \mathrm{n}_{\mathrm{s}}$ represents the number of equal segments used for FT computation. Hence, $\mathrm{X}_{\mathrm{CCS}}^{\mathrm{r}}\left(f_{\mathrm{k}}\right)$ is thus computed as [27];

$$
\mathrm{X}_{\mathrm{CCS}}^{\mathrm{r}}\left(f_{\mathrm{k}}\right)=\sqrt{\left(\mathrm{S}_{\mathrm{x}_{1} \gamma_{12}^{2} \mathrm{x}_{2}}^{\mathrm{r}}\left(f_{\mathrm{k}}\right) \mathrm{S}_{\mathrm{x}_{2} \gamma_{23}^{2} \mathrm{x}_{3}}^{\mathrm{r}}\left(f_{\mathrm{k}}\right) \ldots \mathrm{S}_{\mathrm{x}_{(\mathrm{b}-1)} \gamma_{(\mathrm{b}-1) \mathrm{b}}^{2} \mathrm{x}_{\mathrm{b}}}^{\mathrm{r}}\left(f_{\mathrm{k}}\right)\right)^{\frac{1}{(\mathrm{~b}-1)}}}
$$

In Equation (2), $\gamma_{12}^{2}, \gamma_{23}^{2}, \ldots, \gamma_{(\mathrm{b}-1) \mathrm{b}}^{2}$ respectively denote the coherence [57] between bearings1-2, 2-3, .., (b-1)-b (where $\mathrm{b}=1,2, \ldots, \mathrm{b})$. Also, $\mathrm{S}_{\mathrm{x}_{1} \gamma_{12}^{2} \mathrm{x}_{2}}^{\mathrm{r}}\left(f_{\mathrm{k}}\right) \mathrm{S}_{\mathrm{x}_{2} \gamma_{23}^{2} \mathrm{x}_{3}}^{\mathrm{r}}\left(f_{\mathrm{k}}\right) \ldots .$. $S_{\mathrm{x}_{(\mathrm{b}-1)}}^{\mathrm{r}} \gamma_{(\mathrm{b}-1) \mathrm{b}}^{2} \mathrm{x}_{\mathrm{b}}\left(f_{\mathrm{k}}\right)$ respectively denote the coherent cross-power spectrum between bearings $1-2,2-3, \ldots,(b-1)-b$, which was computed as [27];

$$
S_{\mathrm{x}_{\mathrm{q}} \gamma_{\mathrm{q}(\mathrm{q}+1)}^{2} \mathrm{x}_{\mathrm{q}+1}}^{\mathrm{r}}\left(f_{\mathrm{k}}\right)=\left[\mathrm{X}_{\mathrm{q}}^{\mathrm{r}}\left(f_{\mathrm{k}}\right) \gamma_{\mathrm{q}(\mathrm{q}+1)}^{2} \mathrm{X}_{\mathrm{q}+1}^{\mathrm{r}^{*}}\left(f_{\mathrm{k}}\right)\right]
$$


where $\mathrm{q}=1,2, \ldots,(\mathrm{b}-1)$.

It is evident from Equations (2)-(3) that in the earlier method of CS computation, all the phase information at the intermediate measurement locations will be lost. This is due to the cross power spectrum density (CSD) approach adopted for the earlier data combination process.

The composite bispectrum (CB) is computed as [28, 58-59];

$$
\mathrm{B}\left(f_{\mathrm{l}}, f_{\mathrm{m}}\right)=\frac{\sum_{\mathrm{r}=1}^{\mathrm{n}_{\mathrm{s}}}\left(\mathrm{x}_{\mathrm{CCS}}^{\mathrm{r}}\left(f_{1}\right) \mathrm{X}_{\mathrm{CCS}}^{\mathrm{r}}\left(f_{\mathrm{m}}\right) \mathrm{X}_{\mathrm{CCS}}^{\mathrm{r}^{*}}\left(f_{1}+f_{\mathrm{m}}\right)\right)}{\mathrm{n}_{\mathrm{s}}}
$$

Through the application of a similar computational concept as the CB [28], the composite trispectrum (CT) [58-59] can be computed as;

$$
\mathrm{T}\left(f_{1}, f_{\mathrm{m}}, f_{\mathrm{n}}\right)=\frac{\sum_{\mathrm{r}=1}^{\mathrm{n}_{\mathrm{s}}}\left(\mathrm{x}_{\mathrm{CCS}}^{\mathrm{r}}\left(f_{1}\right) \mathrm{x}_{\mathrm{CCS}}^{\mathrm{r}}\left(f_{\mathrm{m}}\right) \mathrm{X}_{\mathrm{CCS}}^{\mathrm{r}}\left(f_{\mathrm{n}}\right) \mathrm{x}_{\mathrm{CCS}}^{\mathrm{r}^{*}}\left(f_{1}+f_{\mathrm{m}}+f_{\mathrm{n}}\right)\right)}{\mathrm{n}_{\mathrm{s}}}
$$

Where each bispectrum [60-62] component represents the combination of two frequencies (with each possessing amplitude and phase information), $f_{\mathrm{l}}$ and $f_{\mathrm{m}}$ with a third frequency $f_{1}+f_{m}$ which equals the sum of the first two for a signal. Also, each trispectrum [19-24] component represents the combination of three frequencies (with each possessing amplitude and phase information), $f_{\mathrm{l}}, f_{\mathrm{m}}$ and $f_{\mathrm{n}}$ with a fourth frequency $f_{\mathrm{l}}+f_{\mathrm{m}}+f_{\mathrm{n}}$ that equals the sum of the first three for a signal. It is also vital to note that if the frequencies $f_{\mathrm{l}}, f_{\mathrm{m}}$ and $f_{\mathrm{n}}$ are equivalent to the $\alpha$ th, $\beta$ th and $\delta$ th harmonics of the vibration response at the rotor RPM (1x), then the CB and CT components defined in Equations (4)-(5) can also be referred to as $\mathrm{B}_{\alpha \beta}$ and $\mathrm{T}_{\alpha \beta \delta}$. 


\subsection{Improved Method}

The improved CS is also based on CSD, but has been extended to several signals (instead of just two signals applied in the earlier method), called the poly-Coherent Composite Spectrum (pCCS). Unlike the earlier method of data combination described in Section 2.1, the improved computational approach (i.e. pCCS) retains both amplitude and phase information. It is therefore anticipated that this feature (amplitude and phase) retention capability of pCCS will lead to better representation of the entire machine dynamics. Hence, the improved CS is defined as [56];

$$
\mathrm{S}_{\mathrm{pCCS}}\left(f_{\mathrm{k}}\right)=\left(\frac{\sum_{\mathrm{r}=1}^{\mathrm{n}_{\mathrm{s}}} \mathrm{X}_{1}^{\mathrm{r}}\left(f_{\mathrm{k}}\right) \gamma_{12}^{2} \mathrm{X}_{2}^{\mathrm{r}}\left(f_{\mathrm{k}}\right) \gamma_{23}^{2} \mathrm{X}_{3}^{\mathrm{r}}\left(f_{\mathrm{k}}\right) \gamma_{34}^{2} \mathrm{X}_{4}^{\mathrm{r}}\left(f_{\mathrm{k}}\right) \ldots \mathrm{x}_{(\mathrm{b}-1)}^{\mathrm{r}}\left(f_{\mathrm{k}}\right) \gamma_{(\mathrm{b}-1) \mathrm{b}}^{2} \mathrm{X}_{\mathrm{b}}^{\mathrm{r}}\left(f_{\mathrm{k}}\right)}{\mathrm{n}_{\mathrm{s}}}\right)^{(1 / \mathrm{b})}
$$

where, $\mathrm{X}_{1}^{\mathrm{r}}\left(f_{\mathrm{k}}\right), \mathrm{X}_{2}^{\mathrm{r}}\left(f_{\mathrm{k}}\right), \mathrm{X}_{3}^{\mathrm{r}}\left(f_{\mathrm{k}}\right), \mathrm{X}_{4}^{\mathrm{r}}\left(f_{\mathrm{k}}\right), \ldots ., \mathrm{X}_{(\mathrm{b}-1)}^{\mathrm{r}}\left(f_{\mathrm{k}}\right)$ and $\mathrm{X}_{\mathrm{b}}^{\mathrm{r}}\left(f_{\mathrm{k}}\right)$ respectively denote the FT of the rth segment at frequency $f_{\mathrm{k}}$ of the vibration responses at bearings $1,2,3,4, \ldots .,(\mathrm{b}-1)$ and b. Similarly, $\gamma_{12}^{2}, \gamma_{23}^{2}, \gamma_{34}^{2}, \ldots ., \gamma_{(b-1) b}^{2}$ respectively denote the coherence [57] between bearings $1-2,2-3,3-4, \ldots,(\mathrm{b}-1)-\mathrm{b} . \mathrm{S}_{\mathrm{pCCS}}\left(f_{\mathrm{k}}\right)$ is the poly-Coherent Composite Spectrum (pCCS) at frequency, $f_{\mathrm{k}}$.

The CB and CT have also been introduced based on the improved CS [56], and are respectively defined as;

$$
\begin{gathered}
\mathrm{B}\left(f_{\mathrm{l}}, f_{\mathrm{m}}\right)=\frac{\sum_{\mathrm{r}=1}^{\mathrm{n}_{\mathrm{s}}}\left(\mathrm{X}_{\mathrm{pCCS}}^{\mathrm{r}}\left(f_{1}\right) \mathrm{X}_{\mathrm{pCCS}}^{\mathrm{r}}\left(f_{\mathrm{m}}\right) \mathrm{X}_{\mathrm{pCCS}}^{\mathrm{r}^{*}}\left(f_{1}+f_{\mathrm{m}}\right)\right)}{\mathrm{n}_{\mathrm{s}}} \\
\mathrm{T}\left(f_{\mathrm{l}}, f_{\mathrm{m}}, f_{\mathrm{n}}\right)=\frac{\sum_{\mathrm{r}=1}^{\mathrm{n}_{\mathrm{s}}}\left(\mathrm{X}_{\mathrm{pCCS}}^{\mathrm{r}}\left(f_{\mathrm{l}}\right) \mathrm{X}_{\mathrm{pCCS}}^{\mathrm{r}}\left(f_{\mathrm{m}}\right) \mathrm{X}_{\mathrm{pCCS}}^{\mathrm{r}}\left(f_{\mathrm{n}}\right) \mathrm{X}_{\mathrm{pCCS}}^{\mathrm{r}^{*}}\left(f_{\mathrm{l}}+f_{\mathrm{m}}+f_{\mathrm{n}}\right)\right)}{\mathrm{n}_{\mathrm{s}}}
\end{gathered}
$$

In Equations (7)-(8), $\mathrm{X}_{\mathrm{pCCS}}^{\mathrm{r}}$ is the poly Coherent Composite Fourier Transformation (FT) for the rth segment of the measured vibration data from " $b$ " bearing locations at frequency, $f_{\mathrm{k}}$, which was computed as [56]; 


$$
\left.\mathrm{X}_{\mathrm{pCCS}}^{\mathrm{r}}\left(f_{\mathrm{k}}\right)=\left(\mathrm{X}_{1}^{\mathrm{r}}\left(f_{\mathrm{k}}\right) \gamma_{12}^{2} \mathrm{X}_{2}^{\mathrm{r}}\left(f_{\mathrm{k}}\right) \gamma_{23}^{2} \mathrm{X}_{3}^{\mathrm{r}}\left(f_{\mathrm{k}}\right) \gamma_{34}^{2} \mathrm{X}_{4}^{\mathrm{r}}\left(f_{\mathrm{k}}\right) \ldots \mathrm{X}_{(\mathrm{b}-1)}^{\mathrm{r}}\left(f_{\mathrm{k}}\right) \gamma_{(\mathrm{b}-1) \mathrm{b}}^{2} \mathrm{X}_{\mathrm{b}}^{\mathrm{r}}\left(f_{\mathrm{k}}\right)\right)^{(1 / \mathrm{b}}\right)
$$

\section{Proposed Faults Diagnosis Method}

The large number of data usually generated from the computation of $\mathrm{CB}$ and $\mathrm{CT}$ sometimes makes visual diagnosis very difficult and subjective. The analysis becomes even more complicated when dealing with multiple identical (similar components and configurations) rotating machines with slightly different dynamic characteristics (due to variations in their foundation flexibilities) and operating at different speeds. This perhaps explains why some researchers have explored other avenues for simplifying rotating machines FD, through the application of pattern classification tools such as PCA. As previously highlighted in Section 1, PCA [50] is a well-known statistical analysis technique, capable of significantly reducing the dimensionality associated with originally measured data sets through the definition of new variables, often referred to as the principal components (PCs). The first few of the computed PCs usually offer the maximum representation of the variability that exists in the originally measured data [53].

Similarly, the current study proposes a simplified and unified PCA-based FD technique, that will be capable of identifying changes in the operating conditions of several identical 'as installed' rotating machines, irrespective of the variations in their foundation flexibilities and/or operating speeds. Hence, the proposed PCA-based FD technique could eliminate the need for conducting individual analysis (which is often the case in practise) for several identical 'as installed' rotating machines with different foundation flexibilities and speeds. Figure 1 provides a flowchart that illustrates the different steps of the proposed FD technique. The concept of PCA is briefly discussed in Section 3.1, while Section 3.2 provides details of the computational approach for the proposed FD technique.

\subsection{Concept of PCA}

PCA is a multivariate statistical analysis technique that is capable of reducing large interrelated data sets to smaller numbers of variables, without necessarily compromising the variance that exists in the original data set. The fundamental concept of PCA revolves around the projection of data sets onto a subspace of lower dimensionality [63]. PCA explains the 
variance that exists within an original data matrix that is characterised by $\mathrm{n}_{1}$ observations (e.g. number of vibration measurements recorded from a typical rotating machine as part of continuous condition monitoring activities) and $\mathrm{n}_{2}$ variables (e.g. CB and CT faults diagnosis components) in terms of an entirely new set of variables, the PCs.

The concept of PCA has existed for decades, with the initial proposal of the technique dating back to 1933 by Hotelling [64], where it was used for analysing problems related to the statistical dependency between variables in multivariate statistical data obtained from examination scores [63-64]. From then onwards, the relevance and applications of PCA has significantly grown across various disciplines including process monitoring, statistical analysis and faults diagnosis [63-67]. Kresta et al. [68] provides a comprehensive introduction as well as a review of the applications of PCA in process systems engineering, while the studies by Morison [69] and Jackson [64] respectively offered information on the complete treatment of the PCA algorithm. Hence, for the purpose of this study, it suffices to just highlight that PCA was performed and the original data set is eventually expressed as a linear combination of orthogonal vectors along the directions of the PCs.

Let's consider that $n_{1}$ number of independent samples (also referred to as observations) of $n_{2}$ random variables (also referred to as features) which can be represented by an $\mathrm{n}_{1} \mathrm{x} \mathrm{n}_{2}$ matrix, F. The computation of the PCs of $\mathbf{F}$ reduces to the solution of an eigenvalue-eigenvector problem $[63,70]$,

$$
\mathbf{C}_{\mathbf{F}} \mathbf{A}=\mathbf{A} \Lambda
$$

In Equation (10), $\mathbf{C}_{\mathbf{F}}$ is the covariance matrix of $\mathbf{F} . \mathbf{A}$ is the orthogonal matrix whose $\mathrm{m}^{\text {th }}$ column is equivalent to the $\mathrm{m}^{\text {th }}$ eigenvector of $\mathbf{C}_{\mathbf{F}}$ corresponding to the $\mathrm{m}^{\text {th }}$ largest eigenvalue of $\mathbf{C}_{\mathbf{F}} \cdot \boldsymbol{\Lambda}$ is a diagonal matrix, whose $\mathrm{m}^{\text {th }}$ diagonal element is the $\mathrm{m}^{\text {th }}$ largest eigenvalue of $\mathbf{C}_{\mathbf{F}}$. In general as many as $\mathrm{n}_{2}$ PCs can be computed. However, it is expected that the vast majority of variation in $\mathbf{F}$ will be accounted for by $t$ PCs, where $t \ll n_{2}$.

In the current study, PCA is applied for examining the relationship between several experimentally simulated rotating machine conditions. The features used are comprised of computed vibration-based condition monitoring indicators for rotating machines under different states of health. Diagnosis through the application of many condition monitoring (CM) features can be complex and tedious. Hence, for implementing a simplified diagnosis 
approach, reduction in data dimensionality while retaining correlation among them becomes useful. Therefore PCA is used to achieve this objective.

\subsection{Computational Approach of the Proposed FD Technique}

Assuming that vibration data were collected from a rotating machine at various speeds, then the PCA feature matrix F related to Equation (10) can be mathematically expressed as;

$$
\mathbf{F}=\left[\begin{array}{c}
\mathbf{F}_{\mathrm{S}_{1}} \\
\mathbf{F}_{\mathrm{S}_{2}} \\
\vdots \\
\vdots \\
\mathbf{F}_{\mathrm{S}_{\mathrm{N}}}
\end{array}\right]
$$

$\mathbf{F}$ is a feature matrix including feature matrices at different speeds, $\mathbf{F}_{\mathrm{S}_{1}}, \mathbf{F}_{\mathrm{s}_{2}}, \ldots, \mathbf{F}_{\mathrm{S}_{\mathrm{N}}}$, where $\mathrm{s}_{1}$, $\mathrm{s}_{2}, \ldots \ldots, \mathrm{s}_{\mathrm{N}}$ are the different rotor speeds in RPM.

Let's now consider a typical rotating machine, from which sets of vibration data were separately collected under a number of different operating conditions, say " $\mathrm{r}$ " and at a particular rotor speed, $\mathbf{s}_{\mathrm{k}}$. Then the feature matrix $\mathbf{F}_{\mathrm{s}_{\mathrm{k}}}$ can be similarly defined as;

$$
\mathbf{F}_{\mathrm{S}_{\mathrm{k}}}=\left[\begin{array}{c}
\mathbf{F}_{\mathrm{C}_{1}, \mathrm{~s}_{\mathrm{k}}} \\
\mathbf{F}_{\mathrm{C}_{2}, \mathrm{~s}_{\mathrm{k}}} \\
\vdots \\
\vdots \\
\mathbf{F}_{\mathrm{C}_{\mathrm{r}}, \mathrm{s}_{\mathrm{k}}}
\end{array}\right]
$$

where $\mathbf{F}_{\mathrm{C}_{1}, \mathrm{~S}_{\mathrm{k}}}, \mathbf{F}_{\mathrm{C}_{2}, \mathrm{~S}_{\mathrm{k}}}, \ldots . ., \mathbf{F}_{\mathrm{C}_{\mathrm{r}}, \mathrm{S}_{\mathrm{k}}}$ are matrices for each of the experimentally simulated cases, $\mathrm{C}_{1}$, $\mathrm{C}_{2}, \ldots, \mathrm{C}_{\mathrm{r}}$ at rotor speed $\mathrm{s}_{\mathrm{k}}$.

If " $p$ " number of vibration data sets were collected from a rotating machine under a particular machine operating condition (case), $\mathrm{C}_{\mathrm{r}}$, and at a particular rotor speed $\mathrm{s}_{\mathrm{k}}$. Then, the feature matrix $\mathbf{F}_{\mathrm{C}_{\mathrm{r}}, \mathrm{S}_{\mathrm{k}}}$ is computed as;

$$
\mathbf{F}_{\mathrm{C}_{r}, \mathrm{~s}_{\mathrm{k}}}=\left[\begin{array}{ccccc}
\mathrm{X} 1_{\left(\mathrm{C}_{\mathrm{r}}, 1\right), \mathrm{s}_{\mathrm{k}}} & \mathrm{X} 2_{\left(\mathrm{C}_{\mathrm{r}}, 1\right), \mathrm{s}_{\mathrm{k}}} & \mathrm{X} 3_{\left(\mathrm{C}_{\mathrm{r}}, 1\right), \mathrm{s}_{\mathrm{k}}} & \cdots & \mathrm{Xq}_{\left(\mathrm{C}_{\mathrm{r}}, 1\right), \mathrm{s}_{\mathrm{k}}} \\
\mathrm{X} 1_{\left(\mathrm{C}_{\mathrm{r}}, 2\right), \mathrm{s}_{\mathrm{k}}} & \mathrm{X} 2_{\left(\mathrm{C}_{r}, 2\right), \mathrm{s}_{\mathrm{k}}} & \mathrm{X} 3_{\left(\mathrm{C}_{\mathrm{r}}, 2\right), \mathrm{s}_{\mathrm{k}}} & \cdots & \mathrm{Xq}_{\left(\mathrm{C}_{\mathrm{r}}, 2\right), \mathrm{s}_{\mathrm{k}}} \\
\vdots & \vdots & \vdots & \vdots & \vdots \\
\vdots & \vdots & \vdots & \vdots & \vdots \\
\mathrm{X} 1_{\left(\mathrm{C}_{\mathrm{r}}, \mathrm{p}\right), \mathrm{s}_{\mathrm{k}}} & \mathrm{X} 2_{\left(\mathrm{C}_{\mathrm{r}}, \mathrm{p}\right), \mathrm{s}_{\mathrm{k}}} & \mathrm{X} 3_{\left(\mathrm{C}_{\mathrm{r}}, \mathrm{p}\right), \mathrm{s}_{\mathrm{k}}} & \cdots & \mathrm{Xq} \\
\left(\mathrm{C}_{\mathrm{r}}, \mathrm{p}\right), \mathrm{s}_{\mathrm{k}}
\end{array}\right]
$$


where $\mathrm{X} 1, \mathrm{X} 2, \mathrm{X} 3, \ldots ., \mathrm{Xq}$ are individual features for " $\mathrm{p}$ " number of observations under a particular machine operating condition (case) $\mathrm{C}_{\mathrm{r}}$ and at a rotor speed $\mathrm{s}_{\mathrm{k}}$. To further enhance clarity of the PCA feature matrix shown in Equation (13), consider that $B_{\alpha \alpha}, B_{\alpha \beta}, T_{\alpha \alpha \beta}$ and $\mathrm{T}_{\alpha \beta \delta}$ respectively represent $\mathrm{CB}$ and $\mathrm{CT}$ components that have been computed using Equations (7)-(8) for a particular machine operating condition $\left(\mathrm{C}_{\mathrm{r}}\right)$, for " $\mathrm{p}$ " number of measured data sets at rotor speed $s_{\mathrm{k}}$. Hence, the PCA feature matrix can be similarly written as;

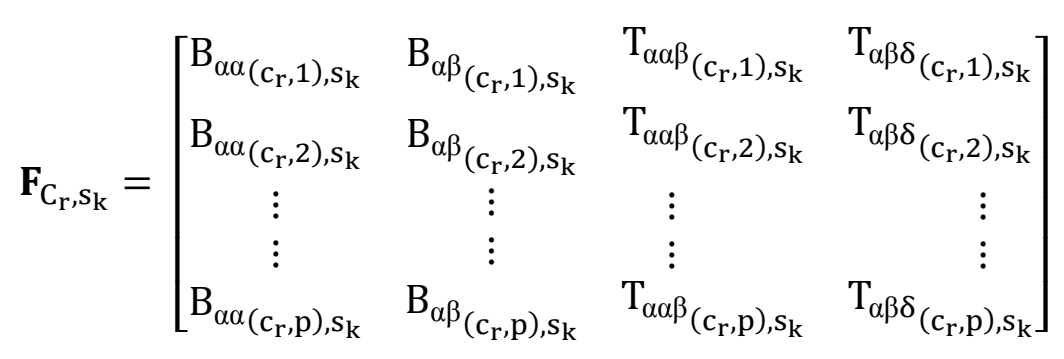

Now, let's further assume that faults diagnosis is to be conducted on a particular rotating machine with "B" number of flexible support (FS) at rotor speeds $s_{k}$, then Equation (12) can be modified thus;

$$
\mathbf{F S}_{\mathrm{B}, \mathrm{S}_{\mathrm{k}}}=\left[\begin{array}{c}
\mathbf{F}_{\mathrm{C}_{1}, \mathrm{~s}_{\mathrm{k}}} \\
\mathbf{F}_{\mathrm{C}_{2}, \mathrm{~S}_{\mathrm{k}}} \\
\vdots \\
\vdots \\
\mathbf{F}_{\mathrm{C}_{\mathrm{r}}, \mathrm{S}_{\mathrm{k}}}
\end{array}\right]
$$

Hence, if the vibration data were then collected at several machine speeds $\left(s_{1}, s_{2}, \ldots, s_{N}\right)$ for the same rotating machine with "B" flexible foundation (FS), then;

$$
\mathbf{F S}_{\mathrm{B}}=\left[\begin{array}{c}
\mathrm{FS}_{\mathrm{B}, \mathrm{S}_{1}} \\
\mathrm{FS}_{\mathrm{B}, \mathrm{S}_{2}} \\
\vdots \\
\vdots \\
\mathrm{FS}_{\mathrm{B}, \mathrm{S}_{\mathrm{N}}}^{\mathrm{T}}
\end{array}\right]^{\mathrm{T}}
$$


Finally, if several identical rotating machines with different flexible foundations $\mathbf{F S}_{1}, \mathbf{F S}_{2}, \ldots$, $\mathbf{F S}_{\mathrm{B}}$ exists, and vibration measurements were conducted on each of them at rotor speeds $\mathrm{s}_{1}$, $s_{2}, \ldots \ldots, s_{N}$. Then the multiple speeds and multiple foundations PCA feature matrix can be written as;

$$
\mathbf{F S}=\left[\begin{array}{c}
\mathbf{F S}_{1} \\
\mathbf{F S}_{2} \\
\vdots \\
\vdots \\
\mathbf{F S}_{\mathrm{B}}
\end{array}\right]^{\mathrm{T}}
$$

Once matrix $\mathbf{F}$ in Equation (11) is constructed, then PCA is carried out as described in Section 3.1.

\section{Experimental Example}

It is often noticed in practice that the dynamic characteristics of "as installed" identical rotating machines in different locations may slightly vary, owing to differences in the flexibilities of their foundations. Hence, the current study attempts to experimentally simulate a similar example, through the aid of two rotating rigs with identical components and configurations (Figure 2), but differ in foundations (FS1 and FS2). FS1 bearings are mounted with $10 \mathrm{~mm}$ thick bright mild steel threaded bars, while FS2 bearings are mounted using 6 mm thick bright mild steel threaded bars (Figure 3). A full description of the experimental rig and faults simulation is provided in Section 4.1.

\subsection{Rig and Faults Simulation}

Since both experimental rigs (FS1 and FS2) [59] are identical, only FS1 is illustrated here (Figure 2). In FS1, two $20 \mathrm{~mm}$ diameter mild steel shafts of lengths $1000 \mathrm{~mm}$ and $500 \mathrm{~mm}$ respectively are rigidly coupled together, while the $1000 \mathrm{~mm}$ shaft is flexibly coupled to an electric motor. Three mild steel balance discs of dimensions $125 \mathrm{~mm}$ (external diameter) x 20 $\mathrm{mm}$ (internal diameter) x $15 \mathrm{~mm}$ (thickness) were evenly mounted across the entire length of the rig. Two balance discs were mounted on the long shaft at $300 \mathrm{~mm}$ from the flexible coupling and $190 \mathrm{~mm}$ from bearing 2 respectively. The third balance disc was then mounted on the short shaft at an equal distance of $210 \mathrm{~mm}$ from both bearings 3 and 4 . The complete 
assembly (rotor, balance discs, couplings, etc.) is supported by four flange-mounted antifriction ball bearings.

A total of six cases were experimentally simulated on both FS1 and FS2, at three machine speeds $(20 \mathrm{~Hz}, 30 \mathrm{~Hz}$ and $40 \mathrm{~Hz})$. The reference case is a healthy case that is associated with some residual misalignment (HRM), as it was very difficult to obtain a perfectly aligned rig. In addition to the HRM case, bent shaft (BS), shaft crack (SC), loose bearing (LB), shaft misalignment (SM) and shaft rub (SR) cases were also simulated on both rigs at all the considered machine speeds. The BS case was simulated by using a fly press to create an axial run-out of $3.4 \mathrm{~mm}$ at the centre of the $1000 \mathrm{~mm}$ shaft. To study the SC case (Figure 4(a)), a crack of $4 \mathrm{~mm}$ (depth) and $0.25 \mathrm{~mm}$ (width) was created on the $1000 \mathrm{~mm}$ shaft using the wire electric discharge machining (EDM) process. As it was very unlikely for the created crack to breath, a $0.23 \mathrm{~mm}$ mild steel shim was inserted in the crack to cause breathing. The LB case (Figure 4(b)) was simulated by loosening the threaded bar fixation nuts on bearing 3. A slight misalignment of $0.4 \mathrm{~mm}$ in the vertical direction near bearing 1 was used to simulate the SM case (Figure 4(c)). For the SR case (Figure 4(d)), two Perspex blades (i.e. one at the top and the other at the bottom of the $1000 \mathrm{~mm}$ shaft respectively) were mounted at a distance of 275 $\mathrm{mm}$ from bearing 1 .

On both FS1 and FS2 rigs, vibration data were measured under of 36 scenarios (i.e. 18 scenarios each for FS1 and FS2 respectively), where each scenario corresponds to specific rig/case/speed combinations (e.g. FS1/HRM/20 Hz). In order to enhance understanding, details of all the considered scenarios are provided in Table 2. Furthermore, 20 sets of measured vibration data (a total of 120 sets of measured vibration data per experimental rig) were collected through the aid of four diagonally mounted PCB accelerometers (one at each bearing location) for further processing through a computational code developed in MATLAB.

\subsection{Experimental Modal Analysis}

Experimental modal analysis is a widely accepted technique for design improvements and useful life enhancement of 'as installed' rotating machines and structures [71-72]. The knowledge of the modal properties of a machine significantly enhances the understanding of the dynamic behaviour of that machine. Similarly, the first few natural frequencies (by 
appearance) of both FS1 and FS2 rigs have been experimentally identified using the impactresponse method. During the experiment, both FS1 and FS2 were excited at two locations with an instrumented hammer (PCB) in both vertical and horizontal directions. The first excitation location was at $209 \mathrm{~mm}$ from both balance discs 1 and 2 (i.e. exactly midpoint of the $1000 \mathrm{~mm}$ shaft), while the second excitation location was at $44 \mathrm{~mm}$ from bearing 3 and disc 3 (Figure 5). During the excitation of FS1 and FS2, the dynamic responses were measured with a PCB accelerometer installed on bearing 2 . Table 1 provides a summary of the identified natural frequencies, while Figures 6-7 show the frequency response function (FRF) amplitude and phase for FS1 and FS2 in both vertical and horizontal directions.

\subsection{Signal Processing}

The CB and CT (computed as per Equations (7)-(8)) of the 20 sets of measured vibration data for each of the 36 scenarios (Table 2) have been post-processed with a MATLAB code using $95 \%$ overlap, frequency resolution $(\mathrm{df})=0.6104 \mathrm{~Hz}$, sampling frequency $\left(f_{\mathrm{s}}\right)=10000 \mathrm{~Hz}$, number of FT data points $(\mathrm{N})=16384$ and 148 number of averages. Typical CB and CT plots of measured vibration data for four scenarios (scenarios 1, 10, 19 and 28 in Table 2) are shown in Figures 8-9. It can be observed that a distinction exists between the reference (scenarios 1 and 19) and fault (scenarios 10 and 28) scenarios, and this observation was fairly consistent for all other scenarios. In the CB plots (Figure 8), the reference scenarios (Figures 8 (a)-(b)) only contained relatively small $B_{11}$ and $B_{12}=B_{21} C B$ components, due to inherent residual misalignments. On the contrary, the fault scenarios (Figures 8(c)-(d)) were associated with several $C B$ components (e.g. $B_{11}, B_{12}=B_{21}, B_{13}=B_{31}, B_{33}$, etc.) of significantly higher amplitudes than observed in the reference scenarios.

It is vital to note that the amplitude of each $\mathrm{CB}$ peak in Figure 8 is a function of two frequency components, usually plotted in the $x y z$ orthogonal axes, with axes $x$ and $y$ respectively representing frequencies, while the amplitude of the $\mathrm{CB}$ component is plotted on the $z$ axis. For instance, the appearance of a $\mathrm{B}_{11} \mathrm{CB}$ peak indicates that the pCCS frequency components $f_{\mathrm{l}}$ and $f_{\mathrm{m}}$ (plotted on both $\mathrm{x}$ and y orthogonal axes) shown in Equation (7) are both equal to the machine speed (also known as $1 \mathrm{x}$ ). Therefore, the $\mathrm{B}_{11} \mathrm{CB}$ peak is a representation of the relation between $f_{\mathrm{l}}(1 \mathrm{x}), f_{\mathrm{m}}(1 \mathrm{x})$ and $f_{\mathrm{l}}+f_{\mathrm{m}}(2 \mathrm{x})$. Similarly, each $\mathrm{B}_{12}=\mathrm{B}_{21} \mathrm{CB}$ peak indicates that the pCCS frequency components $f_{1}$ and $f_{\mathrm{m}}$ shown in Equation (7) are respectively equal to $1 \mathrm{x}$ machine speed and its second harmonic (2x) or vice versa, 
while $f_{1}+f_{\mathrm{m}}$ is equivalent to their sum (3x). Hence, each $\mathrm{B}_{12}=\mathrm{B}_{21} \mathrm{CB}$ peak shows the relation between 1x, 2x and 3x frequency components. Similarly, the CT plots (Figure 9) for the reference (scenarios 1 and 19) and fault (scenarios 10 and 28) scenarios are different. The reference scenarios contain only $\mathrm{T}_{111} \mathrm{CT}$ component (due to some residual misalignment associated with the scenario), while the fault scenarios contained $T_{111}, T_{113}=T_{131}=T_{311}$, etc. This observation was also consistent for all the 36 experimentally simulated scenarios.

Unlike the CB, each CT component is a function of three pCCS frequency components, therefore requiring a 4-dimensional plot. In this study, the spherical plot method earlier suggested by Collis et al. [20] is adopted. In this method, the appearance of individual spheres at certain locations signifies the coupling that exists between the pCCS frequency components at that location. Furthermore, the size of each sphere is a representation of the amplitude of that particular CT component. Hence, $\mathrm{T}_{111}$ CT component in Figures 9(a)-(b) is a representation of the relation between $f_{\mathrm{l}}(1 \mathrm{x}), f_{\mathrm{m}}(1 \mathrm{x}), f_{\mathrm{n}}(1 \mathrm{x})$ and $f_{\mathrm{l}}+f_{\mathrm{m}}+f_{\mathrm{n}}(3 \mathrm{x})$. Also, each $\mathrm{T}_{113}=\mathrm{T}_{131}=\mathrm{T}_{311} \mathrm{CT}$ component in Figures 9(c)-(d) indicates that the pCCS frequency components $f_{1}, f_{\mathrm{m}}$ and $f_{\mathrm{n}}$ shown in Equation (8) are respectively equal to $1 \mathrm{x}, 1 \mathrm{x}$ and $3 \mathrm{x}$ (third harmonic of the machine speed) or vice versa, while $f_{1}+f_{\mathrm{m}}+f_{\mathrm{n}}$ is equivalent to their sum $(5 \mathrm{x})$.

\section{Faults Diagnosis}

It is clear from Figures 8-9 that the CB and CT plots provided distinct features for each of the experimentally simulated scenarios. However, faults diagnosis based on visual observation of the $\mathrm{CB}$ and CT plots alone can be extremely difficult and sometimes subjective. This is due to the appearance of several components in the plots. Hence, the core of the current study is focussed on eliminating or significantly reducing such subjectivities, through the application of the proposed unified faults diagnosis technique described in Section 3.

\subsection{Data Preparation}

The proposed faults diagnosis process was simplified by preparing the feature matrix in stages. Firstly, a matrix was constructed for a particular flexible foundation at a single machine speed, for instance $\mathbf{F S 1}_{20 \mathrm{~Hz}}$. The 20 sets of vibration measurements for each scenario in Table 2 were classified as observations (i.e. rows). Each observation was then 
used to compute two $\mathrm{CB}\left(\mathrm{B}_{11}\right.$ and $\left.\mathrm{B}_{12}\right)$ and two $\mathrm{CT}\left(\mathrm{T}_{111}\right.$ and $\left.\mathrm{T}_{112}\right)$ components amplitudes as per Equations (7)-(8). The computed CB and CT components then represented the features of the matrix (columns). Hence, a matrix containing 4 features $\left(B_{11}, B_{12}, T_{111}\right.$ and $\left.T_{112}\right)$ and 120 observations (20 observations per scenario) was obtained, as detailed by Equation (18). The second stage is concerned with faults diagnosis under multiple machine speeds for a single

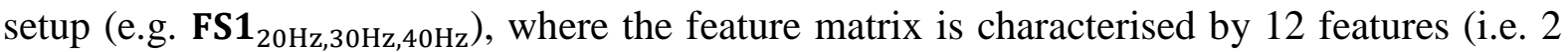
$\mathrm{CB}$ and $2 \mathrm{CT}$ features at each machine speed) and 120 observations. The third and final stage of the data preparation involves the harmonisation of all the features obtained from the second stage for each machine setup. At this stage, a feature matrix containing 120 observations and 24 features (i.e. 12 features each for FS1 and FS2) is constructed. During each of the stages, the constructed feature matrix is eventually fed into a PCA algorithm that computes the PCs. Since maximum representation can be obtained from the first few PCs, a graphical plot of the first and second PCs (Figure 10) is then used for classification of the different scenarios. 


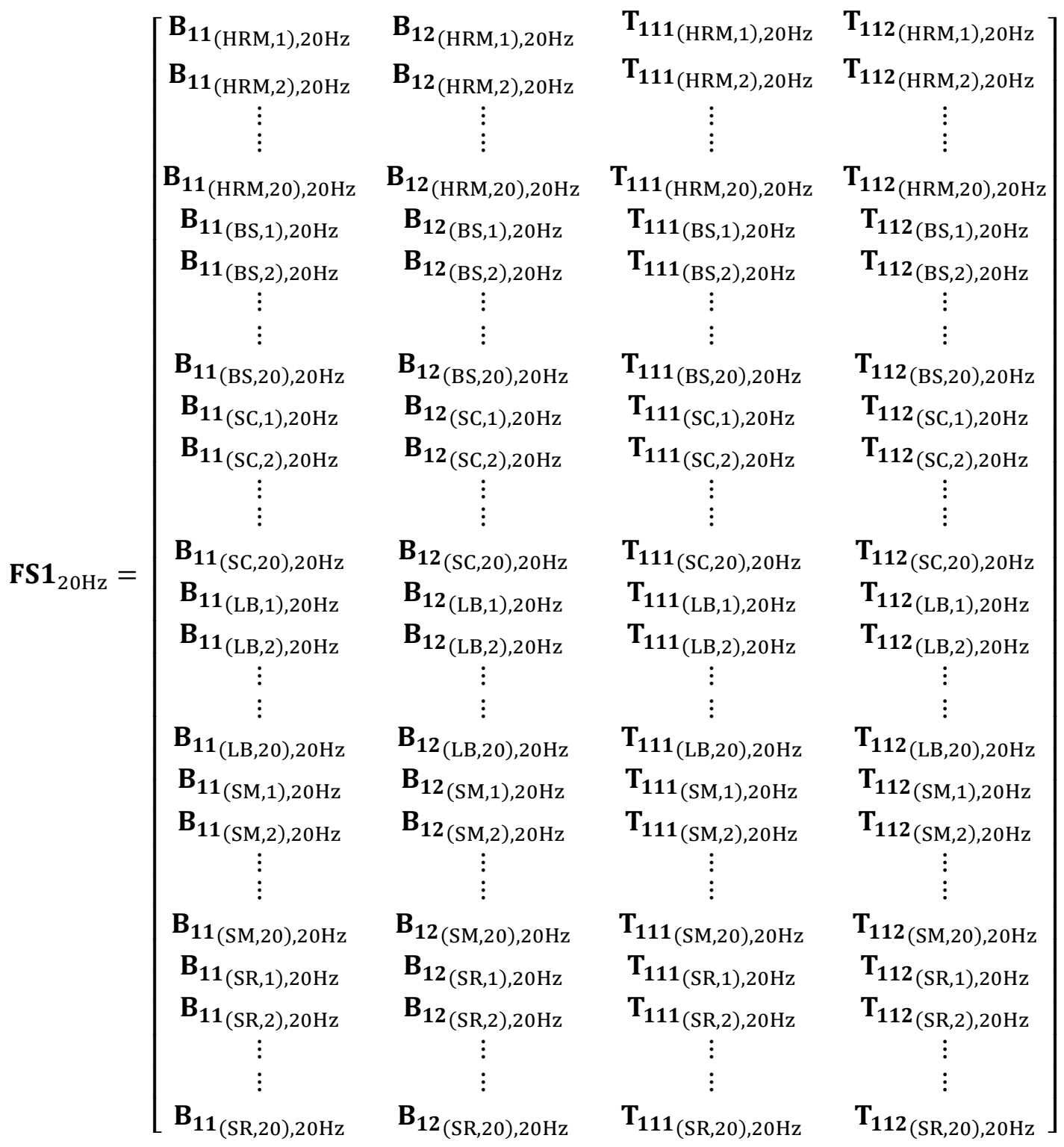

\subsection{Results and Discussion}

Results of the proposed faults diagnosis method for multiple speeds on FS1 and FS2 rigs are respectively shown in Figures 10(a)-(b). With the exception of the slight overlap between the scenarios associated with HRM and SM machine conditions (cases), there was a good separation between all the experimentally simulated cases. However, this overlap was adjudged to be due to the low severity of induced misalignment (i.e. $0.4 \mathrm{~mm}$ ) as well as the presence of residual misalignment in the HRM case. However, the results of the multiple speeds and multiple foundations diagnosis shown in Figure 10(c) provided an even better separation for all scenarios, although a relatively small amount of overlap is still evident between the scenarios associated with HRM and SM cases. Hence, the proposed faults 
diagnosis technique may be useful for significantly reducing the rigour associated with conducting separate analysis for each machine, and at different speeds.

\subsection{Comparison with Earlier Method}

Figure 11 shows the results of similar analyses conducted using CB and CT components amplitudes that were computed based on the earlier method (Equations (4)-(5)). Although appreciable separation was also achieved using the earlier method, however, significantly better results were obtained with the improved method.

\section{Practical Application of the Proposed FD Technique}

In practice, VFD of rotating machines often involves the analysis of measured vibration data that represent the state(s) of a particular machine or group of machines. These measured vibration data are often acquired after pre-defined machine operation periods (also referred to as condition monitoring interval), so as to determine whether a change in machine health has occurred. In order to examine the ability of the proposed technique to diagnose machine faults on a continuous basis, three additional faults diagnosis scenarios (FDS) were considered. The first two faults diagnosis scenarios (FDS1 and FDS2) consider that additional vibration measurements were collected from FS1 and FS2 rotating machines with cracked shafts at $30 \mathrm{~Hz}$ machine speed (i.e. scenarios 8 and 26 in Table 2). The newly acquired vibration data were then used to compute $\mathrm{CB}\left(\mathrm{B}_{11}\right.$ and $\left.\mathrm{B}_{12}\right)$ and $\mathrm{CT}\left(\mathrm{T}_{111}\right.$ and $\left.\mathrm{T}_{112}\right)$ components as per Equations (7)-(8) for FDS1 and FDS2. The computed CB and CT components were then added to the already existing PCA feature matrices described in Equation (13). A combination of the above additional scenarios (FDS1 and FDS2) is also considered for the combined approach (multiple speeds and multiple foundations). The predictions are once again consistent as shown in Figure 12.

\section{Concluding Remarks}

The paper proposes a novel vibration-based fault diagnosis (VFD) technique for detecting and distinguishing common rotor-related faults in rotating machines, which is independent of the machine foundation flexibility and operating speed. The proposed technique aims to 
significantly minimise the rigour and complexities associated with the common practise of performing separate vibration-based analysis for identically configured 'as installed' rotating machines on industrial sites (owing to variations in the flexibilities of foundations and operating speeds). In this study, several sets of vibration data were collected from two identical rotating rigs with different foundation flexibilities and at various machine speeds, through the aid of only four vibration sensors (one per bearing location). For each of the experimental rigs, the measured vibration data under each machine operating condition and speed were then used to independently compute composite bispectrum (CB) and composite trispectrum (CT) components. The computed $\mathrm{CB}$ and $\mathrm{CT}$ components were then used as the features of a principal component analysis (PCA) based algorithm, so as to develop the multiple-speeds and multiple-foundations faults diagnosis technique. The current research presents an integrated VFD method for rotating machines, and further emphasizes the relevance of data combination approaches in the minimisation of the level of subjectivity and human judgements associated with popular techniques such as ordinary amplitude spectra. Hence, the proposed VFD technique presents the potential to significantly enhance maintenance and overall reliability of industrial rotating machines through these summarised advantages:

- Usefulness: with the proposed VFD technique, diagnosis results from one rotating machine are directly applicable to another identically configured rotating machine despite variations in foundation flexibilities and operating speeds. This approach aims to eliminate the common practise of conducting separate analysis for individual rotating machine at different speeds. Hence, historical data and diagnosis results from one rotating machine could be used for faults detection on an identical 'as installed' rotating machine.

- Computational time: in condition monitoring, the computational duration of any chosen technique is very vital, as it may significantly influence the ability to prevent the occurrence of catastrophic machine failures. The proposed VFD technique applies CB and CT components as features in a PCA-based algorithm, which implies that a single composite spectrum is adequate for describing the entire machine dynamics. This significantly reduces the computational rigour and time, when compared to the common practise of computing different spectra at individual vibration measurement locations. 
- Interpretation: interpretation of the results obtained from the proposed VFD technique is quite simple and does not require the services of an expert, since the classification of different machine conditions are very visible.

- Practical application: for any new machine faults diagnosis, the computed features from measured vibration data must be fed into the PCA database. Upon the introduction of the new data, analysis will then be performed to observe the classification of new machine state (healthy or faulty). This diagnosis approach is already demonstrated in the present study.

Furthermore, a comparison of the diagnosis results from CB and CT components computed using the earlier CS method and the improved poly coherent composite spectra (pCCS) was also conducted, and it was clearly observed that $\mathrm{CB}$ and $\mathrm{CT}$ components derived from the pCCS method offered better discrimination between the different experimentally simulated scenarios. In general, the proposed VFD technique is versatile, non-intrusive and computationally efficient, which therefore enhances its potential for usage in industries. However, in order to further confirm the robustness and reliability of the technique, the investigation of more faults with different severities are planned for the near future.

\section{References}

[1] Ishida Y. Cracked rotors: industrial machine case histories and nonlinear effects shown by simple Jeffcott rotor. Mechanical Systems and Signal Processing 2008; 22(4): 805-817.

[2] Moubray J. Reliability-centred maintenance. Industrial Press Inc., 1997.

[3] Grall A, Berenguer C, and Dieulle L. A condition-based maintenance policy for stochastically deteriorating systems. Reliability Engineering and System Safety 2002; 76: 167-180.

[4] Roe S and Mba D. The environment, international standards, asset health management and condition monitoring: An integrated strategy. Reliability Engineering and System Safety 2009; 94: 474-478. 
[5] Jardine AKS, Lin D and Banjevic D. A review on machinery diagnostics and prognostics implementing condition-based maintenance. Mechanical Systems and Signal Processing 2006; 20: 1483-1510

[6] Lee J, Wu F, Zhao W, Ghaffari M, Liao L and Siegel D. Prognostics and health management design for machinery systems-Reviews, methodology and applications. Mechanical Systems and Signal Processing 2014; 42: 314-334.

[7] Heng A, Zhang S, Tan ACC and Mathew J. Rotating machinery prognostics: State of the art, challenges and opportunities. Mechanical Systems and Signal Processing, 2009; 23: 724-739.

[8] Lee J, Ni J, Djurdjanovic D, Qiu H and Liao H. Intelligent prognostics tools and emaintenance. Computers in Industry 2006; 57: 476-489.

[9] Sinha JK and Rao AR. Vibration Based Diagnosis of a centrifugal pump. Structural Health Monitoring 2006; 5(4): 325-332.

[10] Feng $Z$ and Chu F. Nonstationary vibration signal analysis of a hydroturbine based on adaptive chirplet decomposition. Structural Health Monitoring 2007; 6(4): 265-279.

[11] Luo J, Yu D and Liang M. Gear fault detection under time-varying rotating speed via joint application of multiscale chirplet path pursuit and multiscale morphology analysis. Structural Health Monitoring 2012; 11(5): 526-537.

[12] Kaul UK. Modelling and simulation of normal and damage vibration signatures of idealized gears. Structural Health Monitoring 2009; 8(1): 17-28.

[13] Hussain S and Gabbar HA. Fault diagnosis in gearbox using adaptive wavelet filtering and shock response spectrum features extraction. Structural Health Monitoring 2013; 12(2): 169-180.

[14] Dalpiaz G, Rivola A and Rubini R. Effectiveness and sensitivity of vibration processing techniques for local fault detection in gears. Mechanical Systems and Signal Processing, 2000; 14: 387-412.

[15] Pedregal DJ and Carnero MC. Vibration analysis diagnostics by continuous-time models: a case study. Reliability Engineering and System Safety 2009; 94: 244-253. 
[16] Wang WJ and McFadden PD. Early detection of gear failure by vibration analysis I. Calculation of time-frequency distribution. Mechanical Systems and Signal Processing 1993; 7: 193-203.

[17] Meng Q and Qu L. Rotating machinery faults diagnosis using Wigner distribution. Mechanical Systems and Signal Processing 1991; 5: 155-166.

[18] Goldman P and Muszynska A. Application of full spectrum to rotating machinery diagnostics. Orbit 1999; 20: 17-21.

[19] Howard IM. Higher order spectral techniques for machine vibration condition monitoring. Proceedings of the Institution of Mechanical Engineers, Part G: Journal of Aero-space Engineering 1997; 211(4): 211-219.

[20] Collis WB, White PR and Hammond JK. Higher-order spectra: The bispectrum and trispectrum. Mechanical Systems and Signal Processing 1998; 12(3): 375-394.

[21] McCormick AC and Nandi AK. Bispectral and trispectral features for machine condition diagnosis. IEEE Proceedings-Vision, Image and Signal Processing 1999; 146(5): 229-234.

[22] Sinha JK. Higher order spectra for crack and misalignment identification in shaft of a rotating machine. Structural Health Monitoring 2007; 6(4): 325-334.

[23] Yunusa-Kaltungo A and Sinha JK. Combined bispectrum and trispectrum for faults diagnosis in rotating machines. Proceedings of the Institution of Mechanical Engineers, Part O: Journal of Risk and Reliability 2014; 228(4): 419-.428.

[24] Yunusa-Kaltungo A, Sinha JK and Elbhbah K. HOS Analysis of measured vibration data on rotating machines with different simulated faults. In: Proceedings of the $3^{\text {rd }}$ International Conference on Condition Monitoring of Machinery in Non-Stationary Operations, Ferrara, Italy 8-10 May 2013.

[25] Chen YD and Du R. Diagnosing spindle defects using 4-D holospectrum. Journal of Vibration and Control 1998; 4: 717-732.

[26] van der Merwe NT and Hoffman AJ. A modified cepstrum analysis applied to vibrational signals. In: Proceedings of $14^{\text {th }}$ International Conference on Digital Signal Processing (DSP2002) 2002; 2: 283-293, Santorini, Greece. 
[27] Elbhbah K and Sinha JK. Vibration-based condition monitoring of rotating machines using a composite spectrum. Journal of Sound and Vibration 2013; 332(11): 28312845.

[28] Sinha JK and Elbhbah K. A future possibility of vibration-based condition monitoring of rotating machines. Mechanical Systems and Signal Processing 2013; 34(1-2): 231240.

[29] Simani S, Fantuzzi C and Patton RJ. Model-based fault diagnosis in dynamic systems using identification techniques. Springer, London, 2003.

[30] Kerschen G, Worden K, Vakakis AF and Golinval JC. Past, present and future of nonlinear system identification in structural dynamics. Mechanical Systems and Signal Processing 2006; 20: 505-592.

[31] Sinha JK, Lees AW and Friswell MI. Estimating unbalance and misalignment of a flexible rotating machine from a single run-down. Journal of Sound and Vibration 2004; 272: 967-989.

[32] Sekhar AS. Model-based identification of two cracks in a rotor system. Mechanical Systems and Signal Processing, 2004; 18: 977-983.

[33] Sekhar AS. Identification of a crack in a rotor system using a model-based wavelet approach. Structural Health Monitoring 2003; 2(4): 293-308.

[34] Pennacchi P, Bachschmid N and Vania A. A model-based identification method of transverse cracks in rotating shafts suitable for industrial machines. Mechanical Systems and Signal Processing 2006; 20: 2112-2147.

[35] Meireles MRG, Almeida PEM and Simoes MG. A comprehensive review for industrial applicability of artificial neural networks. IEEE Transactions on Industrial Electronics 2003; 50(3): 585-601.

[36] McCormick AC and Nandi AK. Classification of rotating machine condition using artificial neural networks. Proceedings of Institution of Mechanical Engineers, Part C 1997; 211: 439-450. 
[37] McCormick AC and Nandi AK. Real-time classification of rotating shaft loading conditions using artificial neural networks. IEEE Transactions on Neural Networks 1997; 8: 748-756.

[38] Samanta B. Gear fault detection using artificial neural networks and support vector machines with generic algorithms. Mechanical Systems and Signal Processing 2004; 18(3): 625-644.

[39] Sanz J, Perera R and Huerta C. Faults diagnosis of rotating machinery based on autoassociative neural networks and wavelet transforms. Journal of Sound and Vibration 2007; 302(4): 981-999.

[40] Rafiee J, Arvani F, Harifi A, Sadeghi MH. Intelligent condition monitoring of a gearbox using artificial neural network. Mechanical Systems and Signal Processing 2007; 21(4): 1746-1754.

[41] Oberholster AJ and Heyns PS. On-line fan blade damage detection using neural networks. Mechanical Systems and Signal Processing 2006; 20(1): 78-93.

[42] Samanta B and Al-Balushi KR. Artificial neural network based fault diagnostics of rolling element bearings using time-domain features. Mechanical Systems and Signal Processing 2003; 17(2): 317-328.

[43] Cortes C and Vapnik V. Support-vector networks. Machine Learning 1995; 20: 273297.

[44] Burges CJC. A tutorial on support vector machines for pattern recognition. Data Mining and Knowledge Discovery 1998; 2: 121-167.

[45] Yuan SF and Chu FL. Support vector machines-based faults diagnosis for turbo-pump rotor. Mechanical Systems and Signal Processing 2006; 20(4): 939-952.

[46] Yang J, Zhang Y and Zhu Y. Intelligent faults diagnosis of rolling element bearing based on SVMs and fractal dimension. Mechanical Systems and Signal Processing 2007; 21: 2012-2024.

[47] Yang BS, Hwang WW, Ko MH and Lee SJ. Cavitation detection of butterfly valve using support vector machines. Journal of Sound and Vibration 2005; 287(1): 25-43. 
[48] Zio E and Gola G. A neuro-fuzzy technique for fault diagnosis and its application to rotating machinery. Reliability Engineering and System Safety 2009; 94: 78-88.

[49] Mahli A and Gao RX. PCA-based feature selection scheme for machine defect classification. IEEE Transactions on Instrumentation and Measurement 2004; 53(6): $1517-1525$.

[50] Nembhard AD, Sinha JK, Pinkerton AJ and Elbhbah K. Combined vibration and thermal analysis for the condition monitoring of rotating machinery. Structural Health Monitoring 2014; 13(3): 281-295.

[51] Zhang X, Xu CKR, Liang SY, Xie Q and Haynes L. An integrated approach to bearing fault diagnostics and prognostics. In: Proceedings of the American Control Conference 2004; 4: 2750-2755.

[52] Jiang L, Fu X, Cui J and Li Z. Fault detection of rolling element bearing based on principal component analysis. In: Proceedings of the $24^{\text {th }}$ Chinese Control and Decision Conference Tiayuan, China, 23-25 May 2012, pp. 2944-2948.

[53] Li W, Shi T, Liao G and Yang S. Feature extraction and classification of gear faults using principal component analysis. Journal of Quality in Maintenance Engineering 2003; 9(2): 132-143.

[54] Pirra M, Gandino E, Torri A, Garibaldi L and Machorro-Lopez JM. PCA algorithm for detection, localisation and evolution of damages in gearbox bearings. Journal of Physics: Conference Series 2011; 305(1).

[55] Baydar N, Ball A and Payne B. Detection of incipient gear failures using statistical techniques. IMA Journal of Management Mathematics 2002; 13(1): 71-79.

[56] Yunusa-Kaltungo A and Sinha JK. An improved data fusion technique for faults diagnosis in rotating machines. Measurement 2014; 58: 27-32.

[57] Suryam BCBN, Meher KK, Sinha JK and Rao AR. Coherence measurement for early contact detection between two components. Journal of Sound and Vibration 2006; 290(1-2): 519-523.

[58] Yunusa-Kaltungo A and Sinha JK. Coherent composite HOS analysis of rotating machines with different support flexibilities. In: Proceedings of the $10^{\text {th }}$ International 
Conference on Vibration Engineering Technology of Machinery, Manchester, UK, 911 September 2014, pp. 145-153.

[59] Yunusa-Kaltungo A, Sinha JK and Nembhard AD. Use of composite higher order spectra for faults diagnosis of rotating machines with different foundation flexibilities. Measurement 2015; 70: 47-61.

[60] Li Z, Yan X, Yuan C, Zhao J and Peng Z. Fault detection and diagnosis of a gearbox in marine propulsion systems using bispectrum analysis and artificial neural networks. Journal of Marine Science and Application 2011; 10: 17-24.

[61] Fackrell JWA, White PR, Hammond JK, Pinnington RJ and Parsons AT. The interpretation of the bispectra of vibration signals-1: Theory. Mechanical Systems and Signal Processing 1995; 9(3): 257-266.

[62] Fackrell JWA, White PR, Hammond JK, Pinnington RJ and Parsons AT. The interpretation of the bispectra of vibration signals-II: Experimental results and applications. Mechanical Systems and Signal Processing 1995; 9(3): 267-274.

[63] Hotelling H. Analysis of a complex statistical variables into principal components. Journal of Educational Psychology, 1933; 24(6): 417-441.

[64] Jackson JE. A user's guide to principal components. John Wiley and Sons, New York, NY, 1991; 1-25.

[65] Wilson DJH, Irwin GW and Lightbody G. Neural networks and multivariate SPC. IEEE Colloquium on Faults Diagnosis in Process Systems, 1997; 1/5-5/5.

[66] Jia F, Martin EB and Morris AJ. Non-linear principal components analysis for process fault detection. Computers \& Chemical Engineering, 1998; 22: 5851-5854.

[67] Goodman S and Hunter A. Feature extraction algorithms for pattern classification. IEEE Conference Publication on Artificial Neural Network, 1999; 738-742.

[68] Kresta JV, McGregor JF and Marlin TE. Multivariate statistical monitoring of process operating performance. The Canadian Journal of Chemical Engineering, 1991; 69(1): $35-47$.

[69] Morison DF. Multivariate statistical methods. McGraw-Hill, New York, NY. 
[70] Jolliffe IT. Principal component analysis. Springer Series in Statistics, $2^{\text {nd }}$ Edition, Springer, New York, 2002.

[71] Ewins DJ. Basics and state-of-the-art of modal testing. Sadhana 2000; 25(3): 207220.

[72] Ewins DJ. Modal testing-theory, practice and application. 2nd edition, Research Studies Press, UK, 2000.

\section{List of Figures}

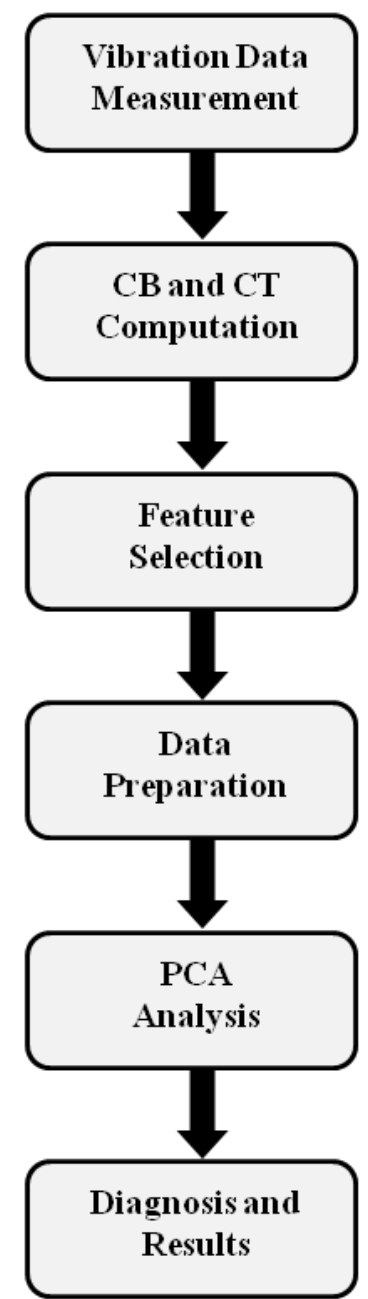

Figure 1 Proposed faults diagnosis process flow chart 


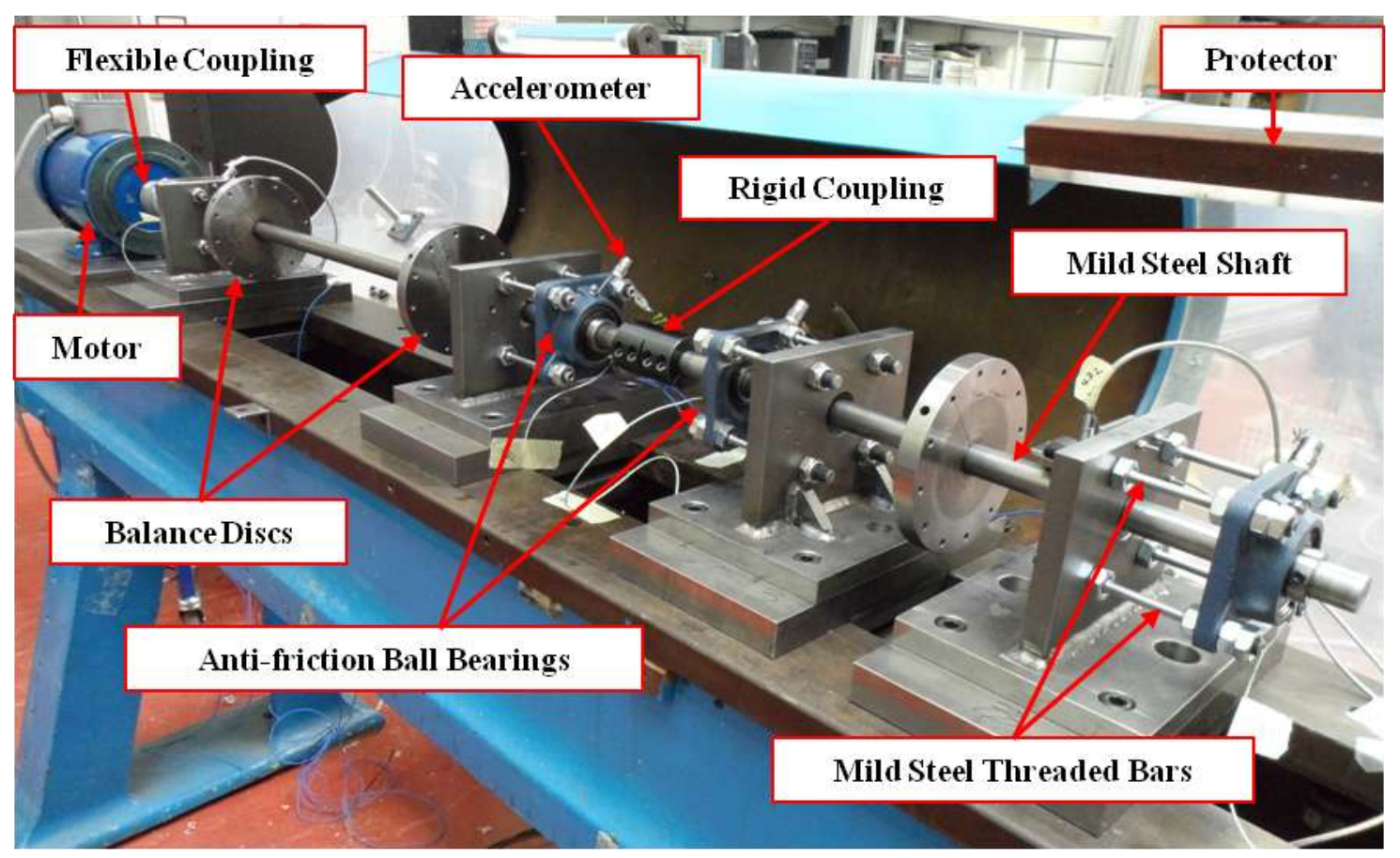

Figure 2 Experimental rig

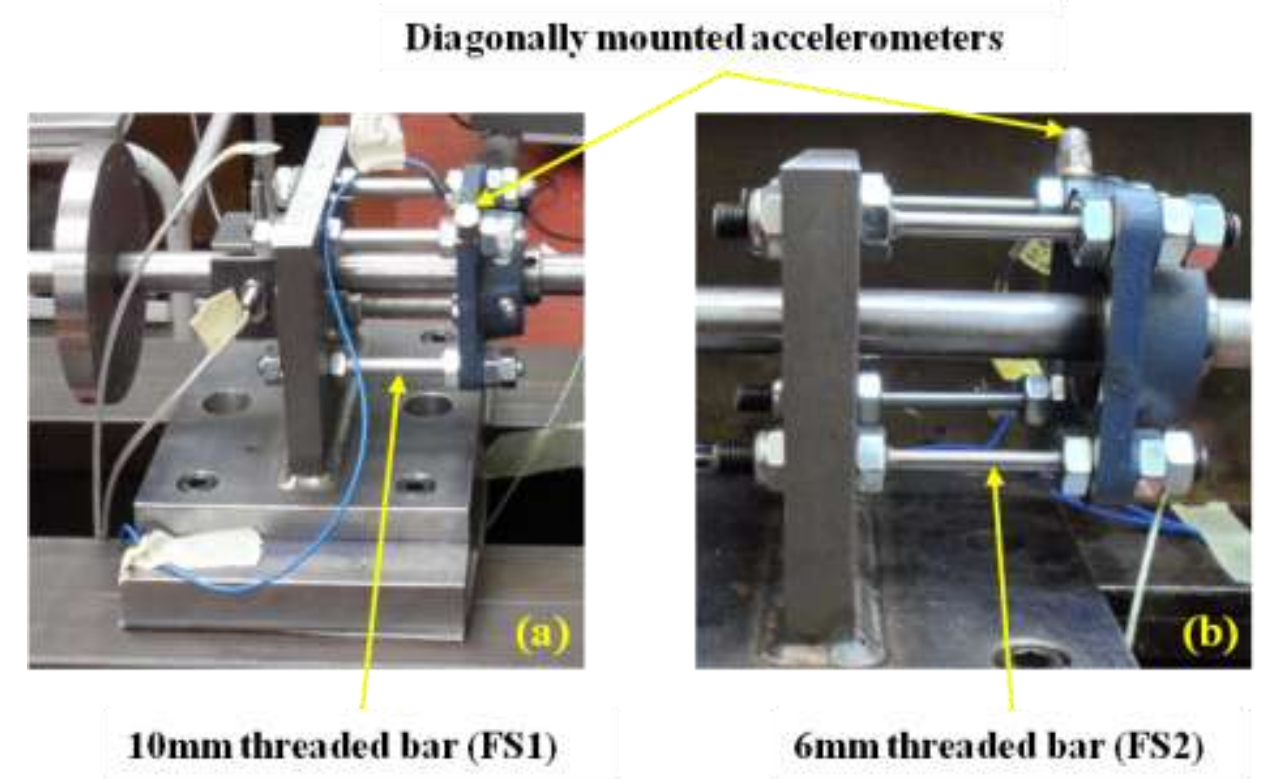

Figure 3 Different rig supports [59]. (a) FS1, (b) FS2 

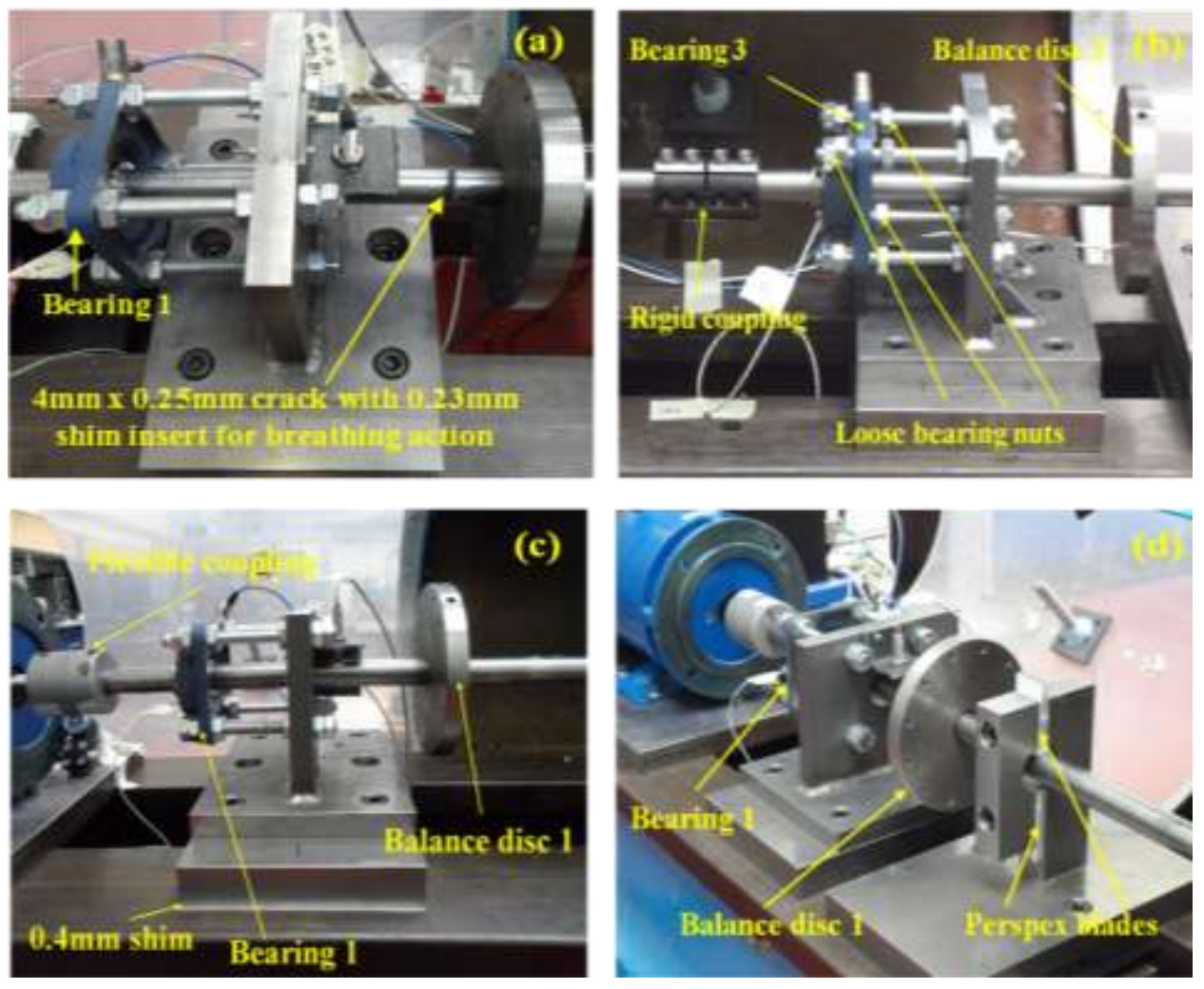

Figure 4 Experimentally simulated cases [58]. (a) SC, (b) LB, (c) SM, (d) SR

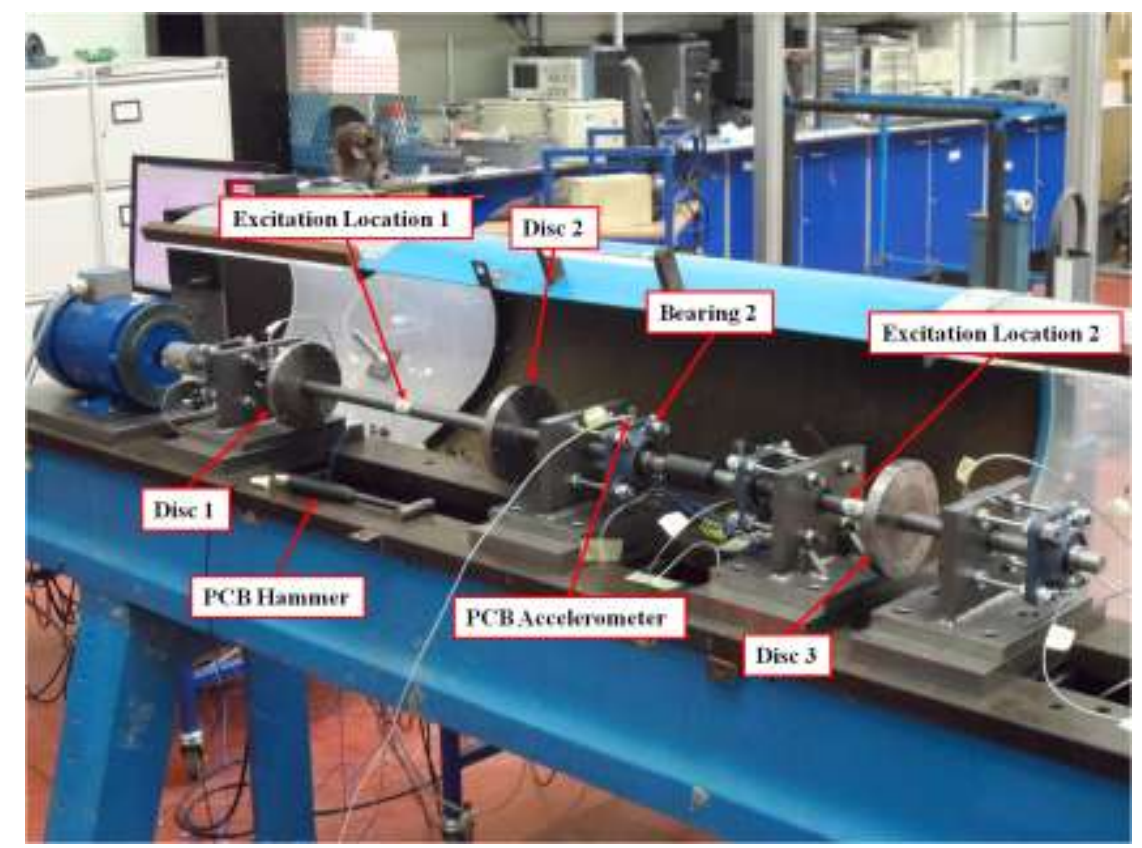

Figure 5 Experimental setup for modal test 

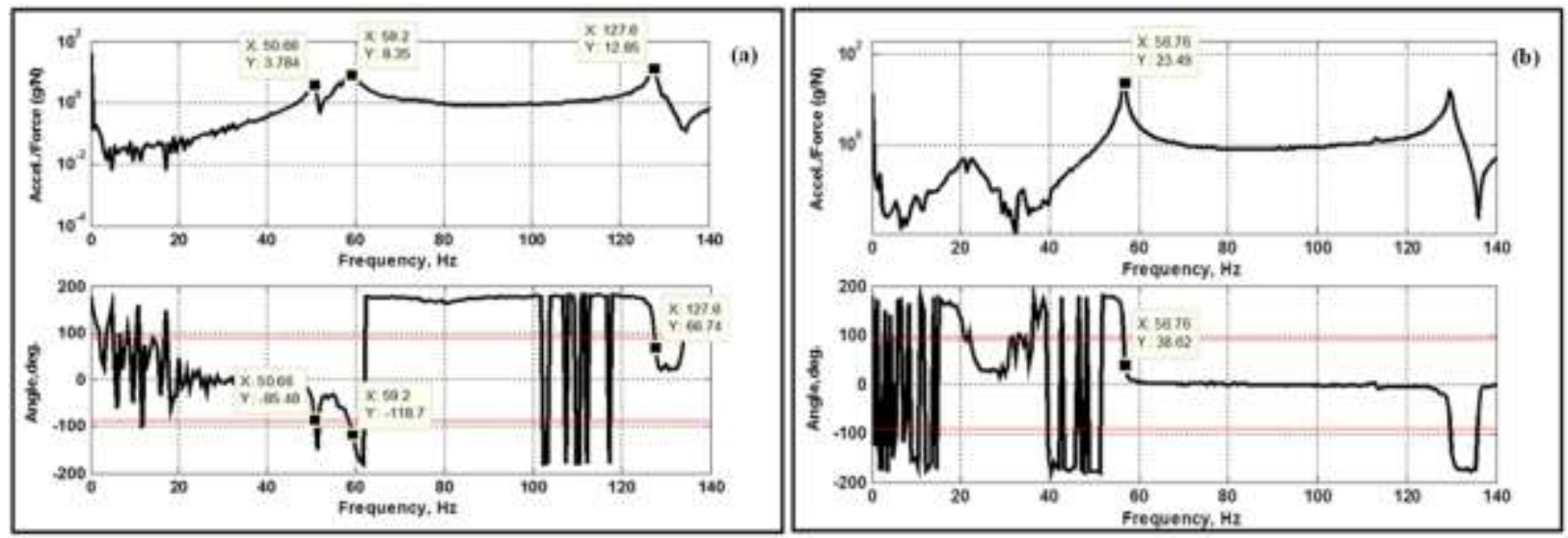

Figure 6 Typical FRF amplitude and phase plots for FS1, measured at bearing 2 (a) vertical direction (b) horizontal direction
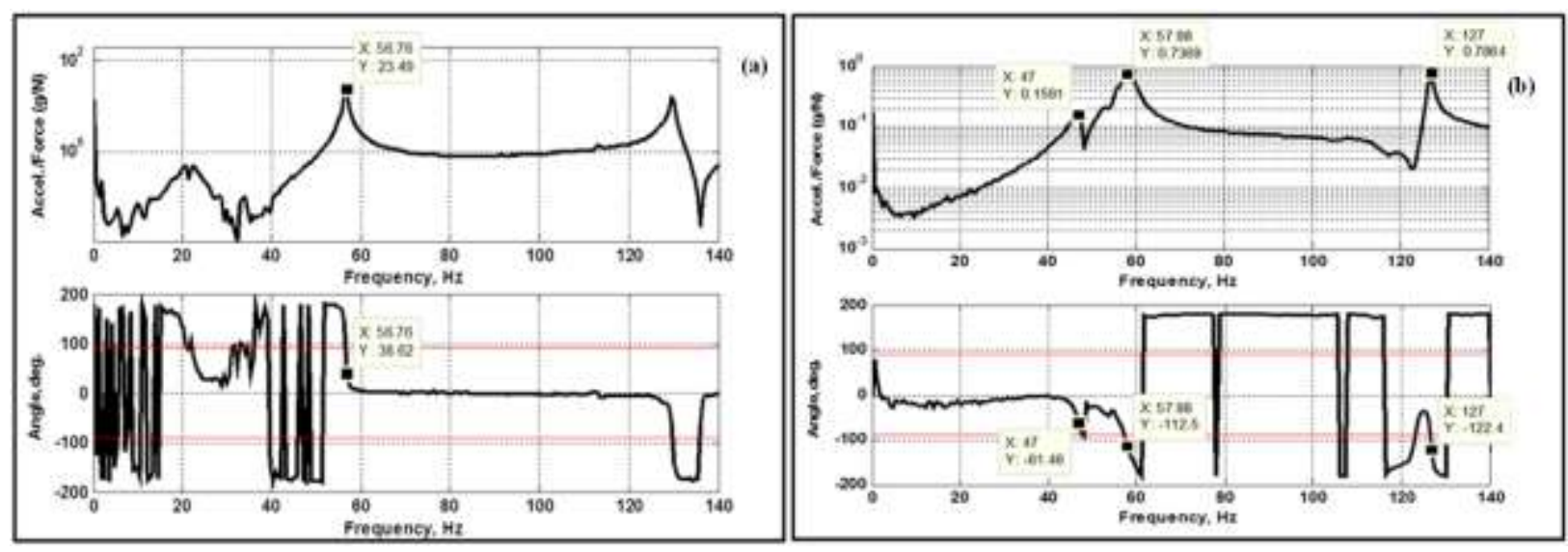

Figure 7 Typical FRF amplitude and phase plots for FS2, measured at bearing 2 (a) vertical direction (b) horizontal direction 

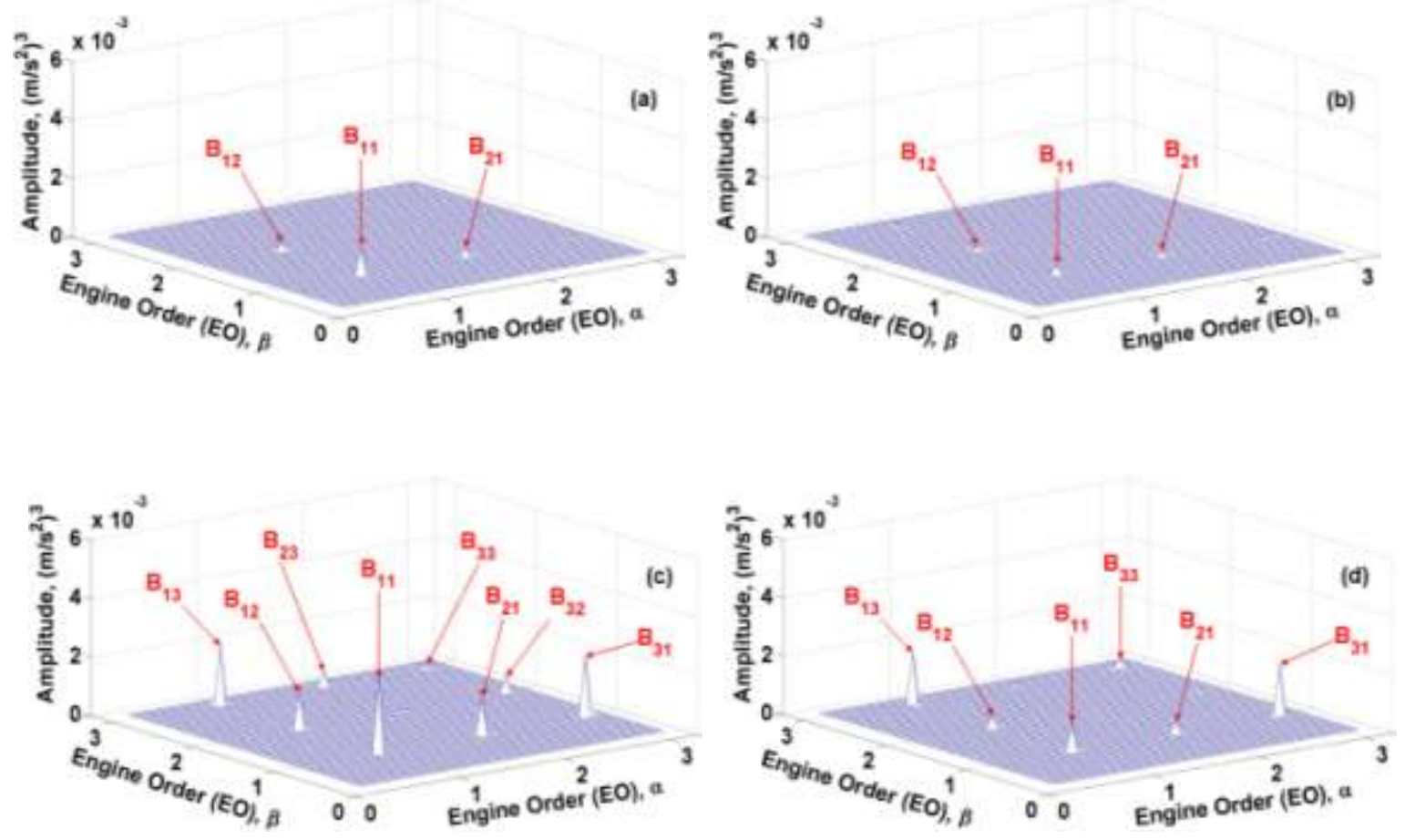

Figure 8 Typical CB plots for FS1 and FS2 at $20 \mathrm{~Hz}$. (a) HRM (FS1), (b) HRM (FS2), (c) LB (FS1), (d) LB (FS2)
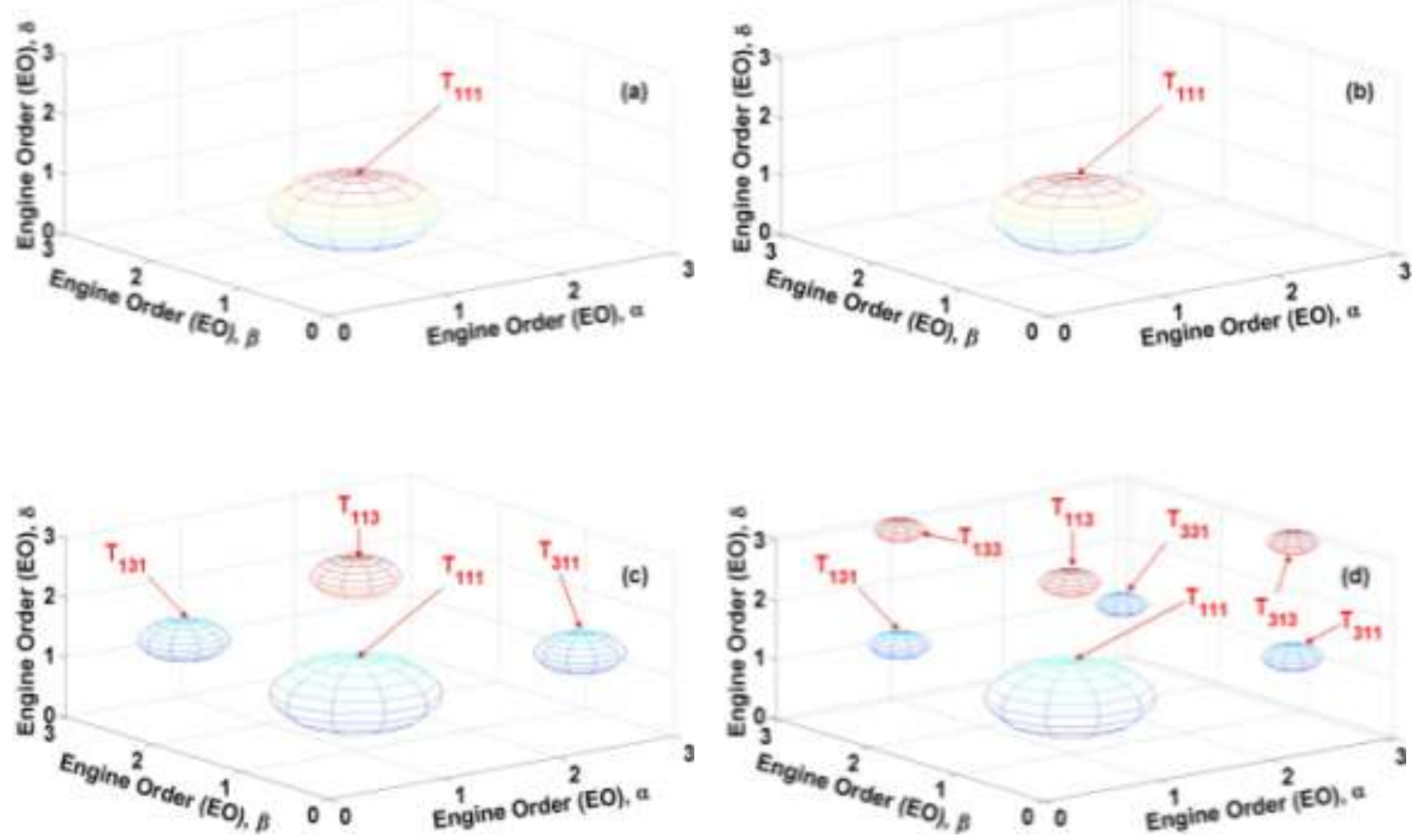

Figure 9 Typical CT plots for FS1 and FS2 at 20 Hz. (a) HRM (FS1), (b) HRM (FS2), (c) LB (FS1), (d) LB (FS2) 

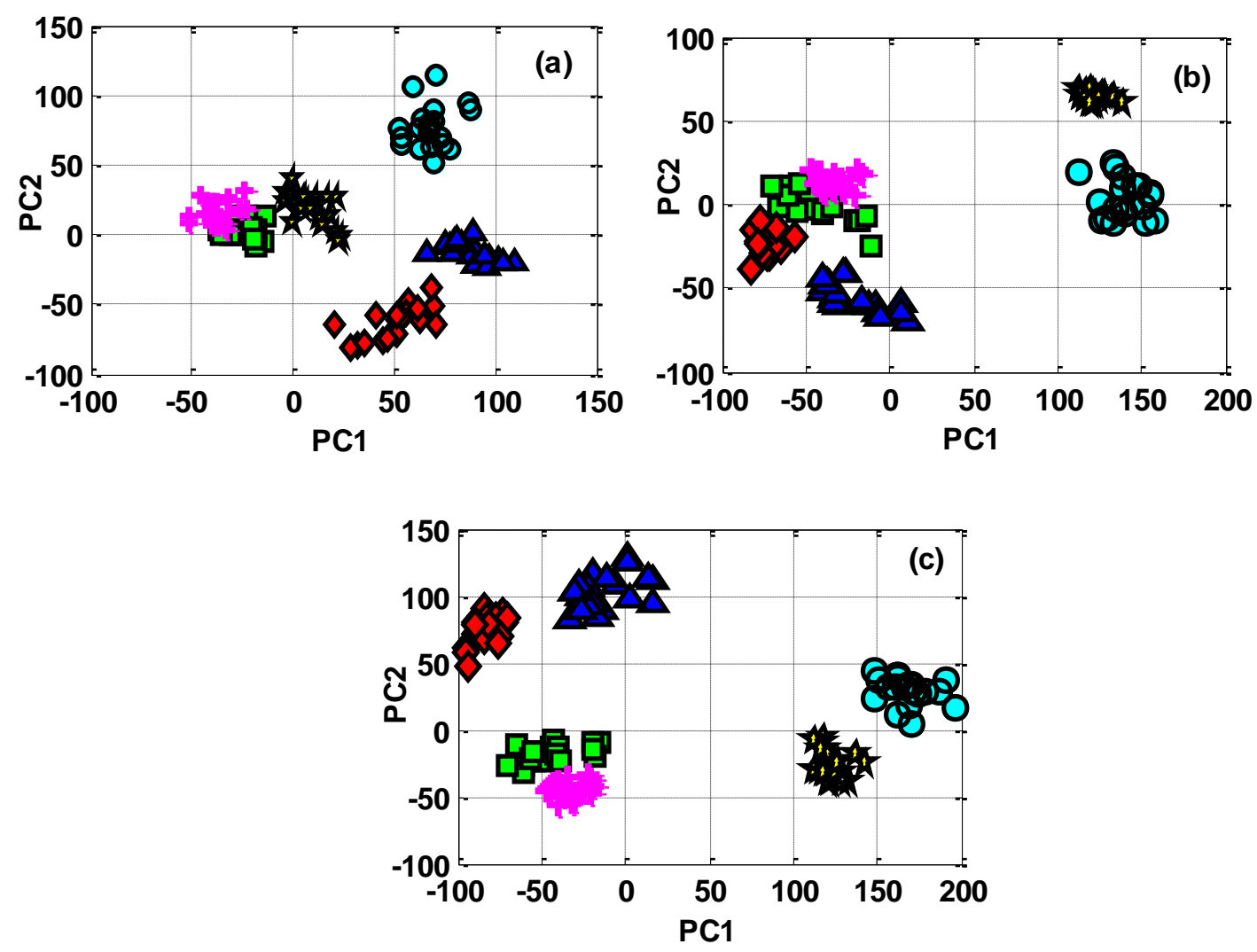

\begin{tabular}{|llllllllllll}
\hline 口 & HRM & & BS & O & SC & A & LB & + & SM & $\bullet$ & SR \\
\hline
\end{tabular}

Figure 10 Proposed faults diagnosis, (a) Multiple speeds - FS1 setup (b) Multiple speeds FS2 foundation (c) Multiple speeds and multiple foundations 

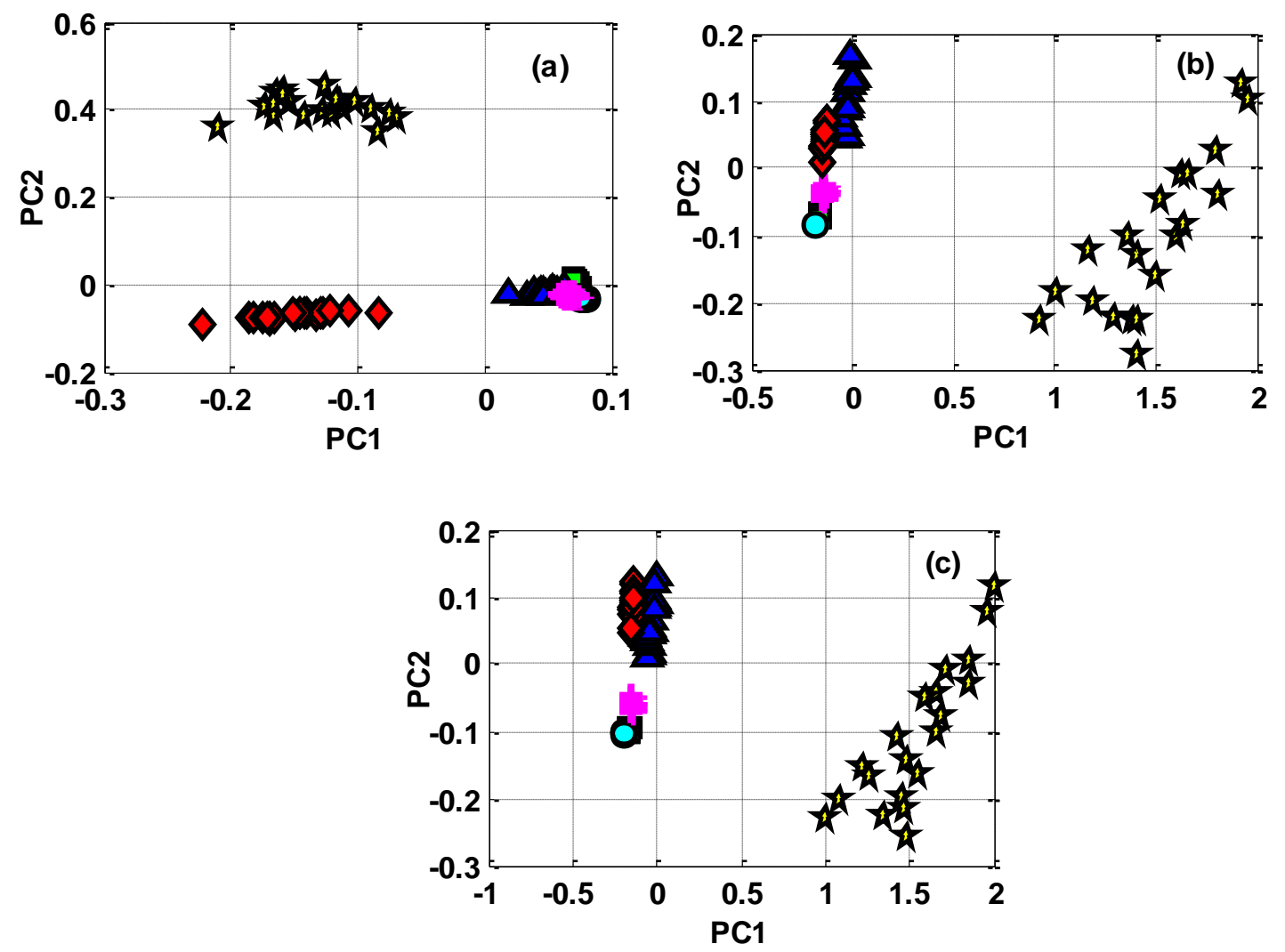

\begin{tabular}{|lllllllllllll|}
\hline $\mathbf{\square}$ & HRM & & BS & O & SC & A & LB & + & SM & $\diamond$ & SR \\
\hline
\end{tabular}

Figure 11 Faults diagnosis with earlier CB and CT method, (a) Multiple speeds - FS1 setup (b) Multiple speeds - FS2 setup (c) Multiple speeds and multiple foundations 

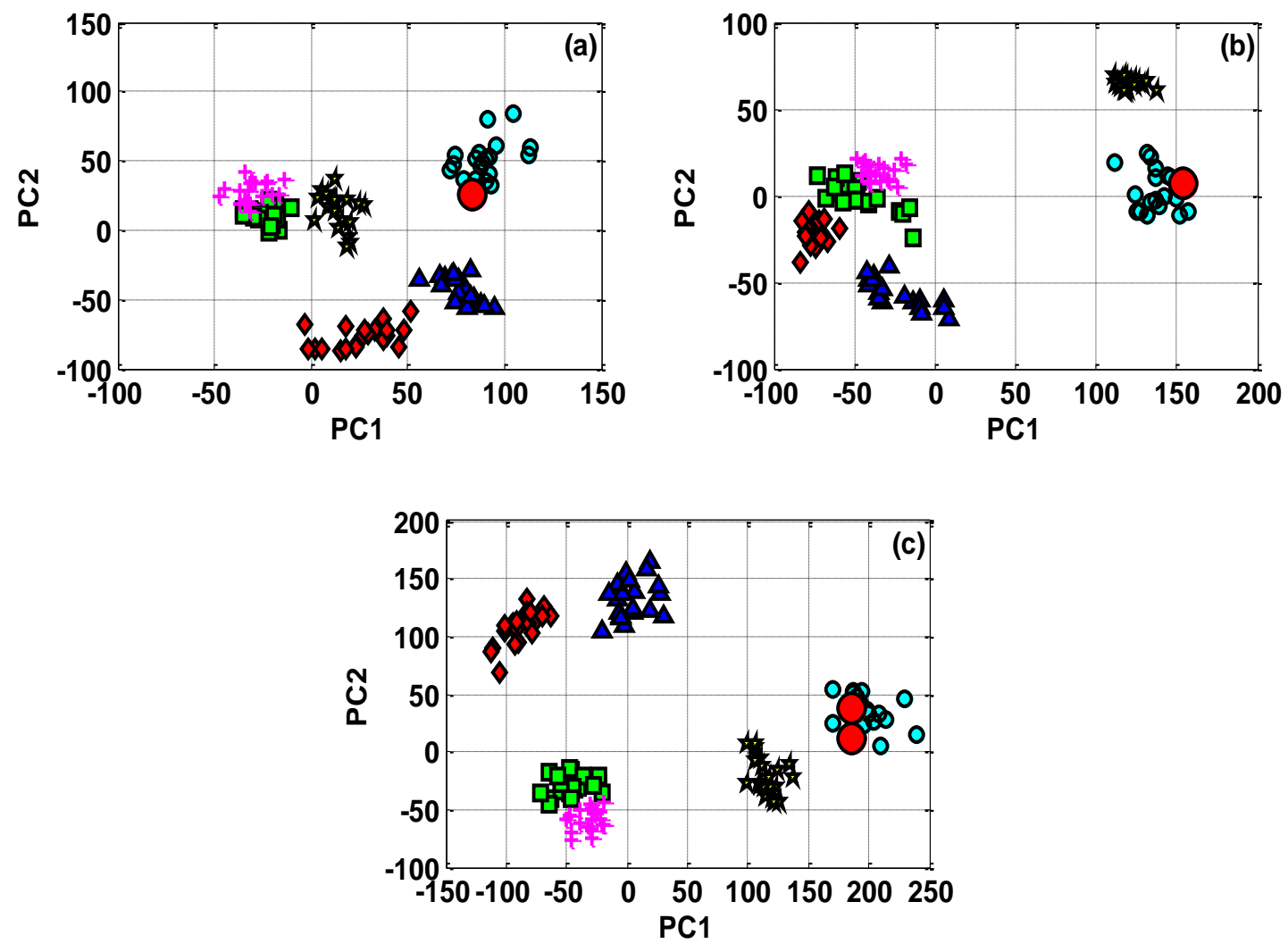

\begin{tabular}{|llllllllllllll|}
\hline 口 & RM & $\star$ & BS & $\circ$ & CS & $\boldsymbol{4}$ & LB & + & SM & $\bullet$ & SR & $\bullet$ & FDS \\
\hline
\end{tabular}

Figure 12 Continuous faults diagnosis, (a) Multiple speeds - FS1 setup (b) Multiple speeds FS2 foundation (c) Multiple speeds and multiple foundations

\section{List of Tables}

Table 1 Experimentally identified natural frequencies for FS1 and FS2

\begin{tabular}{ccccc}
\hline \multirow{2}{*}{ Experimental Set-up } & \multicolumn{4}{c}{ Natural Frequencies (Hz) } \\
\cline { 2 - 5 } & $\mathbf{1}^{\text {st }}$ & $\mathbf{2}^{\text {nd }}$ & $\mathbf{3}^{\text {rd }}$ & $\mathbf{4}^{\text {th }}$ \\
\hline FS1 & 50.66 & 56.76 & 59.2 & 127.6 \\
\hline FS2 & 47 & 55.54 & 57.98 & 127 \\
\hline
\end{tabular}


Table 2 Experimental scenarios for FS1 and FS2

\begin{tabular}{|c|c|c|c|c|c|c|c|c|c|c|c|c|}
\hline \multirow{3}{*}{ Rig Speed } & \multicolumn{12}{|c|}{ Scenarios } \\
\hline & \multicolumn{6}{|c|}{ FS1 } & \multicolumn{6}{|c|}{ FS2 } \\
\hline & HRM & BS & $\mathrm{SC}$ & LB & SM & SR & HRM & BS & $\mathrm{SC}$ & LB & SM & SR \\
\hline $20 \mathrm{~Hz}$ & 1 & 4 & 7 & 10 & 13 & 16 & 19 & 22 & 25 & 28 & 31 & 34 \\
\hline $30 \mathrm{~Hz}$ & 2 & 5 & 8 & 11 & 14 & 17 & 20 & 23 & 26 & 29 & 32 & 35 \\
\hline $40 \mathrm{~Hz}$ & 3 & 6 & 9 & 12 & 15 & 18 & 21 & 24 & 27 & 30 & 33 & 36 \\
\hline
\end{tabular}

